\title{
The microbiome of Escherichia coli and culture-negative nonsevere clinical mastitis: Characterization and associations with linear score and milk production
}

\author{
A. K. Vasquez, ${ }^{1}$ E. K. Ganda, ${ }^{1}$ M. B. Capel, ${ }^{2}$ S. Eicker, ${ }^{3}$ P. D. Virkler, ${ }^{1}$ R. C. Bicalho, ${ }^{1}$ and D. V. Nydam ${ }^{1 *}$ \\ ${ }^{1}$ Department of Population Medicine, College of Veterinary Medicine, Cornell University, Ithaca 14853 \\ ${ }^{2}$ Perry Veterinary Clinic, Perry, NY 14530 \\ ${ }^{3}$ Valley Agricultural Software, King Ferry, NY 13081
}

\section{ABSTRACT}

Culture-negative and Escherichia coli cases are uncommonly treated in pathogen-based protocols for nonsevere mastitis. High-throughput 16S rRNA sequencing might reveal the presence of other pathogens and can provide information on microbial diversity. The objective was to explore the milk microbiome at the time of the mastitis event (enrollment) and its association with survival in the herd, milk production, and postevent linear score (LS) for cows with clinical mastitis characterized as negative or $E$. coli by culture. Fifty $E$. coli-positive and 35 culture-negative samples from cases were enrolled. No cases were treated with antimicrobials. All E. coli-positive quarters were characterized as transient; microbiological culture of samples taken 15 $\mathrm{d}$ postmastitis were negative for this organism. However, a difference in $\alpha$-diversity (Shannon index) was present between enrollment and follow-up samples (3.8 vs. 5.1). When $\alpha$-diversity was explored for enrollment E. coli samples, no relationship was observed between the Shannon indices of these samples and postmastitis LS. Alpha-diversity of the enrollment samples was lower for E. coli-positive cows that subsequently had greater losses in milk production. This difference was explained by a greater relative abundance of the family Enterobacteriaceae (67.8 vs. 38.4\%) for cows that dropped in production. Analysis of composition of the microbiome identified one phylum, Proteobacteria, that differed between E. coli-positive cows that dropped in production and those that did not. Evaluation of $\beta$-diversity found no statistical relationship between postmastitis LS and the microbiome. When evaluating

Received May 14, 2018.

Accepted September 23, 2018.

*Corresponding author: dvn2@cornell.edu $\alpha$ - and $\beta$-diversities and composition of the microbiomes for culture-negative quarters, no associations were found for milk production changes and postmastitis LS. Three cows did not remain in the herd, limiting the ability to analyze survival. The findings suggest that a contributing factor to negative outcomes in $E$. coli-positive cows is relative abundance of this pathogen, and that no single or collective group of bacterial families is associated with milk production changes or postmastitis LS in culture-negative quarters. Although additional studies should be performed, the absence of associations between outcomes explored and microbial profiles in this study suggests that we are not missing opportunities by not treating nonsevere $E$. coli or culture-negative mastitis cases.

Key words: mastitis, Escherichia coli, milk microbiome, metagenomics

\section{INTRODUCTION}

As outlined in a 100-yr review of the Journal of Dairy Science, mastitis, the inflammation or infection of the mammary gland, remains the most common bacterial disease on the majority of dairies and its treatment or prevention accounts for the majority of antimicrobials administered to adult dairy cattle (Pol and Ruegg, 2007; Stevens et al., 2016; Ruegg, 2017). Pathogenbased treatment strategies for clinical mastitis (CM) have been useful in decreasing antibiotic use without consequential negative outcomes (Lago et al., 2011a,b; Vasquez et al., 2017). These strategies use aerobic culture results to guide therapy, often resulting in treatment of only gram-positive organisms. Pathogen-based protocols were developed in response to research that suggested a lack of efficacy of intramammary antimicrobials for gram-negative mastitis pathogens (Pyörälä et al., 1994; Suojala et al., 2013). Additionally, the use of antimicrobials on culture-negative quarters can be difficult to justify; provided that 25 to $35 \%$ of cases produce negative results, accurate diagnostic tools 
should replace the routine use of treating all cases before etiologic diagnosis (Hogeveen et al., 2011; Oliveira and Ruegg, 2014). Though aerobic culture remains the gold standard for diagnosis, it is inherently biased toward bacteria that can grow in specific conditions, and for organisms that are present in high numbers in the commonly aliquoted inoculum of $10 \mu \mathrm{L}$.

Alternatively, sequencing and analysis of hypervariable regions in the $16 \mathrm{~S}$ rRNA gene can assess bacterial diversity in milk from affected cows and might elucidate what organisms are contributing to culture-negative and other etiologic disease (Kuehn et al., 2013; Oikonomou et al., 2014; Oultram et al., 2017). Profiles generated from mastitic human and bovine milk suggest that $\mathrm{CM}$ is associated with dysbacteriosis and a robust microbial community in the mammary gland might aid in the prevention of an IMI (Fernández et al., 2013; Oikonomou et al., 2014). A dysbacteriosis detected using sequencing methods might provide information for treatment or culling decisions; however, analyses of the relationships of bacterial composition and cow-level outcomes should also be assessed. Although relationships to production and health outcomes were not investigated, Kuehn et al. (2013) identified bacterial genera that might be responsible for the microbial differences between mastitic and healthy quarters. The presence of some of genera suggested that well-known mastitis pathogens were present below culture detection thresholds. Alternatively, if a dominant pathogen such as Escherichia coli is present, its disruption to the diversity of the microbiome might contribute to the development of clinical disease. As such, one could speculate that the nontreatment of these profiles in a selective treatment protocol represents a missed opportunity. Independent of treatment, the effect of microbial profiles at diagnosis on health and production outcomes must be assessed. In this study, we chose to focus on E. coli and culture-negative mastitic quarters, as in a selective treatment protocol, these animals do not receive intramammary treatment.

Our objective was to explore the microbiome of cows with nonsevere $E$. coli $\mathrm{CM}$ to determine if microbial profiles differ between cows that had positive [survival in the herd, no drop in milk production, or a next-test linear score (LS) of $<4.0$ ] or negative (culling from the herd, a drop in milk production, or a next-test LS of $\geq 4.0$ ) outcomes when not treated. Our second objective was to explore the microbiome of cows with nontreated culture-negative CM to determine if microbial profiles differ between cows that had positive or negative outcomes as defined above. Characterizing these associations will improve our understanding of CM, allowing for more effective treatment strategies.

\section{MATERIALS AND METHODS}

\section{Study Animals}

Mild to moderate CM cases that were positive for $E$. coli or negative for growth on aerobic culture were assessed for inclusion at a 3,500-Holstein-cow commercial dairy in central New York between December 2014 and April 2015 under Institutional Animal Care and Use Committee approval. The resulting cases were a subset from a larger group $(\mathrm{n}=725)$ of clinical cases that were used to investigate a pathogen-based treatment protocol. Herd characteristics including distribution of mastitis pathogens are described elsewhere (Vasquez et al., 2017). This farm bedded with digested manure solids $(36 \% \mathrm{DM})$ treated with $6 \%$ quick lime. The Jvac coliform vaccine (Merial Limited, Duluth, GA) was given at dry off, 3 to 4 wk pre-calving, and 3 to $4 \mathrm{wk}$ postfreshening according to the label directions. The farm used DHIA services, which included monthly SCC and milk weights. Health records were recorded using Dairy Comp 305 (Valley Ag Software, Tulare, CA).

\section{Case Definition}

Each mastitis case was detected by trained on-farm employees by observing abnormalities in milk such as changes in consistency and color, or udder signs including hard, swollen, or red quarters. Cows exhibiting severe symptoms such as depression, anorexia, dehydration, or fever received systemic antimicrobials and antiinflammatories and were excluded from the study. Other exclusion criteria were treatment with antimicrobials or antiinflammatories in the previous $15 \mathrm{~d}$ or impending sale of the animal.

\section{Sample Collection and Treatment Assignment}

At the time of mastitis detection and before milking, the teat end of the affected quarter was scrubbed with an individual alcohol-soaked gauze, the quarter was stripped, and approximately $5 \mathrm{~mL}$ of milk was collected into a sterile culture tube. Samples were taken by trained farm personnel. These samples were defined as enrollment samples. The tube was labeled and promptly placed in a $5^{\circ} \mathrm{C}$ refrigerator. Culture results within $24 \mathrm{~h}$ of sample collection were achieved through the use of daily sample pick-up via the Quality Milk Production Services (QMPS) program at the Animal Health and Diagnostic Center in Ithaca, New York. This study focused on nontreated clinical quarters; only culture-negative and quarters positive for $E$. coli were included in the analysis. To characterize the chronicity of E. coli-positive quarters, postenrollment samples 
were targeted to be retrieved from the same quarter 14 $\pm 3 \mathrm{~d}$ after each mastitis event. These samples were taken by QMPS technicians in the same manner as previously described, and defined as follow-up samples.

\section{Microbiological Methods}

Standard culture technique was performed on all samples by QMPS employees according to National Mastitis Council guidelines for identification of aerobic organisms and Mycoplasma spp. (National Mastitis Council, 2017). Briefly, $0.01 \mathrm{~mL}$ of milk was streaked on trypticase soy agar containing $5 \%$ sheep blood and $1 \%$ esculin (PML Microbiologicals; Mississauga, ON, Canada) and MacConkey's agar (Hardy Diagnostics, Santa Maria, CA), and plates were incubated aerobically at $37^{\circ} \mathrm{C}$ for 18 to $24 \mathrm{~h}$. Colonies from pure cultures were subjected to matrix-assisted laser desorption/ ionization time-of-flight (MALDI-TOF) using a Bruker MALDI-TOF Biotyper version 3.1.66 (Bruker Corp., Billerica, MA). Confidence levels were assigned by the machine software by referencing the Bruker 5989 RUO bacterial library. Levels accepted for species identification were $\geq 2.0$ and for genus identification between 1.8 and 2.0. Diagnosis and confirmation of an IMI by culture of a single quarter milk sample was based on standard published definitions (Dohoo et al., 2011). Confirmation of E. coli as the etiologic cause was defined as the isolation of one or more colonies from 10 $\mu \mathrm{L}$ of milk.

Any cow not following treatment protocol was excluded from all analyses; the distribution of cows in each group was described in Vasquez et al. (2017). Cows in the study were followed up for postmastitis milk production, postmastitis LS, and survival in the herd. All values and dates were retrieved from farm management, DHIA test-day records, or Dairy Comp 305. Each cow was followed until the end of its current lactation, the date it was culled, or $60 \mathrm{~d}$ postenrollment, whichever arrived first. All cows remained in the treatment pen until milk returned to normal visual appearance.

\section{Metagenomic Analysis}

DNA Extraction, Isolation, and Purification. Milk samples were thawed, vortexed, and a 2-mL aliquot was removed for isolation and purification. The samples were centrifuged at $4^{\circ} \mathrm{C}$ and $16,000 \times g$ for 3 min. The supernatant and fat were discarded and DNA was extracted from the pellet using the Powerfood DNA Isolation Kit (Mo Bio Laboratories, Carlsbad, CA) according the manufacturer's protocol, which includes mechanical and enzymatic lysis steps. Concentration of
DNA was first evaluated using a NanoDrop ND-1000 spectrophotometer (NanoDrop Technologies, Wilmington, DE) with the following wavelengths: 230,260 , and $280 \mathrm{~nm}$.

Amplification of the Hypervariable Region of the $16 S$ rRNA Gene. Amplification of the V4 hypervariable region of the bacterial $16 \mathrm{~S}$ rRNA gene was performed via PCR using the primers $515 \mathrm{~F}$ and $806 \mathrm{R}$ optimized for the Illumina MiSeq platform and 140 different 12 bp error-correcting Golay barcodes (Illumina Inc., San Diego, CA) as previously described (Gilbert et al., 2010; Caporaso et al., 2012). Positive and negative controls were included in each plate and consisted of the following, respectively: DNA extracted from a pure colony of Streptococcus uberis (ATCC 700407) and DNA-free water. Amplicons were generated in triplicate using $3 \mu \mathrm{L}$ of DNA template, $1 \times$ EconoTaq Plus Green Master Mix (Lucigen, Middleton, WI), and $5 \mu M$ of each primer. Amplification of the $16 \mathrm{~S}$ rRNA gene consisted of the following: an initial denaturing step of $94^{\circ} \mathrm{C}$ for 3 min followed by 35 cycles of $94^{\circ} \mathrm{C}$ for $45 \mathrm{~s}$, $50^{\circ} \mathrm{C}$ for $1 \mathrm{~min}, 72^{\circ} \mathrm{C}$ for $90 \mathrm{~s}$, and an elongation step of $72^{\circ} \mathrm{C}$ for $10 \mathrm{~min}$. Amplicons from the triplicate wells were pooled and subsequently purified with a Gel/PCR DNA Fragment Extraction kit (IBI Scientific, Peosta, IA) according to the manufacturer's guidelines. Amplicons and controls were visualized by electrophoresis using $1.2 \%$ (wt/vol) agarose gels stained with $0.5 \mathrm{mg} /$ $\mathrm{mL}$ of ethidium bromide. Quantification of amplicon DNA was performed using the Qubit Fluorimeter (Life Technologies Corporation, Carlsbad, CA).

Library Preparation and Sequence Analysis. Amplicons from individual samples were standardized to the same concentration and pooled. Equimolar libraries were sequenced on the Illumina MiSeq platform in 2 runs using the MiSeq reagent kit V2 for 300 cycles. Each run included 279 samples from multiple bovine projects and one sequencing control (purified barcoded PCR product of DNA extracted from S. uberis). The raw single-end sequences generated were processed through the Quantitative Insights Into Microbial Ecology 2 (QIIME2; version 2017.9) open source software pipeline (Caporaso et al., 2010a). Quality control was performed on demultiplexed sequences using the DADA2 pipeline, which removed phiX artifacts and chimeric sequences, and a truncation at 180 bases was chosen (Callahan et al., 2016). Open-reference taxonomic assignment into operational taxonomic units (OTU) with 97\% identity was performed using UCLUST, RDP classifier, PyNAST, and Greengenes databases (DeSantis et al., 2006; Caporaso et al., 2010b; Edgar, 2010; McDonald et al., 2012). Within-sample diversity, $\alpha$-diversity, was assessed using the Shannon index calculated in a randomly selected subset of the OTU database obtained 
through the script "diversity $\alpha$-group-significance" after creation of rooted and unrooted phylogenetic trees using the mafft and FastTree programs in QIIME2 at a rarefication level of 1,500 reads per sample. Shannon index evaluates richness and abundance of OTU. Between-sample diversity, $\beta$-diversity, was assessed through phylogenetic-based weighted and unweighted UniFrac distances, calculated in QIIME2 through the script "diversity beta-group-significance," and the distance matrix produced was used for comparisons between outcome groups (Lozupone and Knight, 2005).

\section{Statistical Comparisons}

The UNIVARIATE procedure in SAS version 9.4 (SAS Institute Inc., Cary, NC) was used for descriptive analysis. Tabulation of relative abundances for the 24 most abundant bacterial families was performed using the tabulate function of JMP Pro 12 (SAS Institute Inc.). The remaining families were compiled into a single category defined as other. As relative abundances and measures of diversity were not normally distributed, outcomes of interest were evaluated using nonparametric statistics. The outcomes investigated were culling or sale before $60 \mathrm{~d}$ postmastitis, drop in milk production between the test days before and after the CM event, and LS at the test day after the mastitis event. Linear score is a transformation of SCC, calculated as $[\ln (\mathrm{SCC} / 100) / \ln (2)]+3$ (Ali and Shook, 1980). Linear score and loss in milk production outcomes were also explored as dichotomous outcomes: loss in production was dichotomized into a reduction of $>2.2 \mathrm{~kg}$ or not, and LS was dichotomized into $\geq 4.0$ or $<4.0$. A milk production drop of $2.2 \mathrm{~kg}$ was chosen (approximately $5 \mathrm{lbs}$ ) for several reasons. First, it accounts for more than the milk production declines of a normal midlactation curve between test days, and it is an economically meaningful loss for dairy herds. Additionally, the distribution of cattle for each outcome was similar. A LS cutoff of 4.0 (SCC of 200,000 cells/mL) was chosen as it is commonly used as an indicator of IMI (Dohoo and Leslie, 1991; Schepers et al., 1997). The PROC CORR procedures of SAS were used to determine Spearman's rank correlation to test whether $\alpha$-diversity of the samples was associated with the outcomes. This test was also used to determine whether $\alpha$-diversity of the samples was associated with the relative abundance of Enterobacteriaceae or Ruminococcaceae in the enrollment samples or associated with the change in relative abundance of Enterobacteriaceae between the enrollment and follow-up samples in the E. coli group. When $\alpha$-diversity comparisons were made between enrollment and follow-up samples, the Wilcoxon test was used to account for repeated measures. The NPAR-
1WAY (Kruskal-Wallis or Wilcoxon test) procedure in SAS was used to determine the association between the relative abundance of Enterobacteriaceae or Ruminococcaceae and dichotomous outcomes. Changes in relative abundance of Enterobacteriaceae and the relationships to dichotomous outcomes were also explored. The PROC REG in SAS was used to explore the relationship between 3 continuous variables: change in milk production, Shannon index, and relative abundance of Enterobacteriaceae in the enrollment samples.

Multivariate analysis of the milk microbial profile was performed in QIIME2 and $\mathrm{R}$ ( $\mathrm{R}$ Core Team, Vienna, Austria). UniFrac distances are quantitative measures of community dissimilarity that incorporate phylogenetic relationships between the samples. Unweighted UniFrac distances (most efficient for detecting abundance changes in rare lineages) and weighted UniFrac distances (most sensitive to detect changes in abundant lineages) were both investigated. Initially, the nonparametric test, permutational ANOVA, was used on UniFrac distance matrices in QIIME2 to determine relationships to the outcomes (Anderson, 2001). Analysis of similarities (ANOSIM) was performed on nonrarefied data using the vegan package in $\mathrm{R}$. Groups that had statistical differences using ANOSIM underwent analysis of composition of microbiomes in QIIME2 to identify which OTU were driving these differences. Visualization of the differences was permitted by performing principal coordinate analysis of weighted UniFrac distances in EMPeror (Vázquez-Baeza et al., 2013). To test whether $\beta$-diversity of the samples in each data set (culture-negative samples and E. coli enrollment samples) was associated with the dichotomized production outcomes, the "diversity beta-group-significance" command was used in QIIME2 to compare the UniFrac distance matrices between the categorical descriptors. Descriptive analyses of results are presented as medians, means, and standard errors.

\section{RESULTS}

\section{Characterization of E. coli Cases}

Whereas a convenience sample of 35 cases of culturenegative mastitis were selected for metagenomic analysis, all nontreated, nonsevere E. coli cases from Vasquez et al. (2017) were considered for characterization and analysis. Of the 489 qualifying mild and moderate quarter-level mastitis events outlined in Vasquez et al. (2017), 113 were culture-positive for E. coli (23\%). A total of 56 cases were assigned to the nontreated group (49.6\% of E. coli cases). Of these, 6 were omitted from the analysis for the following reasons: cow was dried early $(\mathrm{n}=4)$, cow died $(\mathrm{n}=1)$, and quarter became 
Table 1. Cow and data retrieval descriptors for cows experiencing nonsevere mastitis characterized as Escherichia coli or negative on aerobic culture and the relationship to postmastitis linear score or drops in milk production

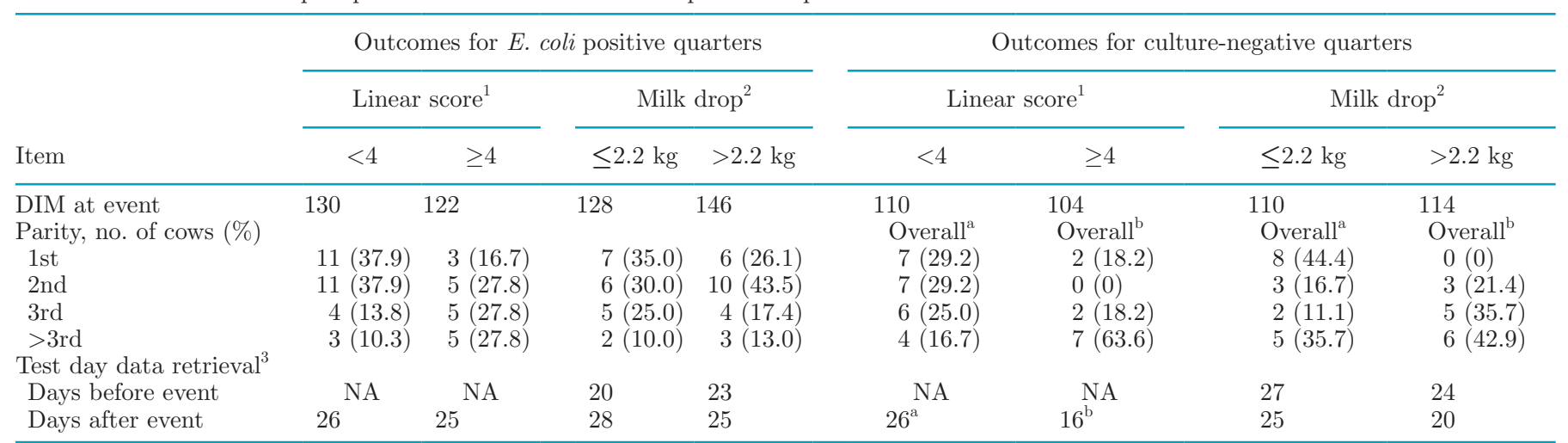

${ }^{\mathrm{a}, \mathrm{b}} \mathrm{S}$ Samples within a row and for an individual outcome with different superscripts differ. Student's $t$-test for continuous data, Pearson's chisquared for parity comparison $(P<0.05)$.

${ }^{1}$ At DHIA test 8 to $43 \mathrm{~d}$ after the mastitis event, dichotomized.

${ }^{2}$ Milk production drop between test day previous to mastitis event ( 8 to $43 \mathrm{~d}$ ) and test day after the mastitis event ( 8 to $43 \mathrm{~d}$ ), dichotomized.

${ }^{3}$ Mean number of days before or after the mastitis event that data were retrieved to analyze linear score and milk production drop. NA $=$ not applicable; linear score was retrieved only as a postmastitis measurement.

agalactic $(\mathrm{n}=1)$. The remaining 50 cases were each contributed by an individual cow. The mean number of days between mastitis event and follow-up culture was $15.2(\mathrm{SE}=0.3 \mathrm{~d}$; range, $12-21 \mathrm{~d})$. The most commonly reported follow-up culture result was negative $(\mathrm{n}=$ $44,88 \%$ ). The remaining 6 cases were characterized as Streptococcus spp., CNS, yeast, gram-positive bacillus, Streptococcus dysgalactiae, or Trueperella pyogenes. No follow-up cultures were characterized as E. coli.

\section{Descriptive Data: All Samples}

Mean DIM and distribution of parity at mastitis event for each outcome can be seen in Table 1. These variables were not different between outcome groups for E. coli-positive quarters. Days in milk at mastitis event were also similar for all outcome groups for culture-negative quarters. For these quarters, a greater number of higher parity cows experienced negative outcomes (LS $\geq 4$, milk drop) as compared with the number of higher parity cows that experienced positive outcomes $(P=$ 0.03 and $P=0.007$, respectively). As milk drop was calculated as the difference in milk production between the test days before and after the mastitis event, the distribution of days surrounding the event and each test day was evaluated. The number of test days before and after the mastitis event for data retrieval was normally distributed. Means and medians were similar; means by outcome group are reported in Table 1. Overall, for $E$. coli samples, the prior test day occurred at $22 \mathrm{~d}$ before the mastitis event ( $\mathrm{SE}=1.5 \mathrm{~d}$; range 8-41 d), whereas the postmastitis test day occurred $24.5 \mathrm{~d}$ after the event $(\mathrm{SE}=1.4 \mathrm{~d}$; range 8-45 d). For culture-negative samples, the prior test day occurred at $26.0 \mathrm{~d}$ before the mastitis event ( $\mathrm{SE}=1.4 \mathrm{~d}$; range, 9-41 d), whereas the postmastitis test day occurred $22.6 \mathrm{~d}$ after the event $(\mathrm{SE}=2.0 \mathrm{~d}$; range, 8-41 d). No statistical association was observed between the number of days between the prior test date and the mastitis date and the milk drop outcome for either culture group (Table 1). However, when the same was evaluated for the postevent test date for culture-negative cows, a fewer number of days between the mastitis date and postevent test day was associated with the higher LS category $(P=0.03)$.

\section{Sequencing Results and Taxonomic Classification}

On average across all samples, $15.4 \%$ of all reads were not classified on the family level $(\mathrm{SE}=0.9 \%)$; the number of unclassified reads at the genus level was $37.7 \%(\mathrm{SE}=1.4 \%)$. A total of 3,193,730 sequences were used for downstream analysis of the E. coli-positive samples ( $\mathrm{n}=100$ samples; 50 enrollment samples and 50 follow-up samples). The mean number of reads was 31,937 reads/sample $(\mathrm{SE}=1,654)$. A total of 981,958 sequences were used for downstream analysis of the culture-negative samples $(\mathrm{n}=35)$. The mean number of reads was 28,056 reads/sample $(\mathrm{SE}=2,886)$.

The most abundant families in the enrollment samples that were culture positive for E. coli were Enterobacteriaceae $($ mean $=55.7 \%, \mathrm{SE}=5.6 \%)$, Ruminococcaceae $($ mean $=11.9 \%, \mathrm{SE}=2.3 \%$,$) , Lachnospiraceae$ $($ mean $=4.7 \%, \mathrm{SE}=0.6 \%)$, Corynebacteriaceae (mean $=2.5 \%, \mathrm{SE} 0.7 \%)$, Bacteroidaceae $($ mean $=2.2 \%, \mathrm{SE}=$ $0.4 \%)$, Aerococcaceae $($ mean $=1.8 \%, \mathrm{SE}=0.4 \%)$, Paraprevotellaceae $($ mean $=1.6 \%, \mathrm{SE}=0.3 \%)$, Peptostrep- 

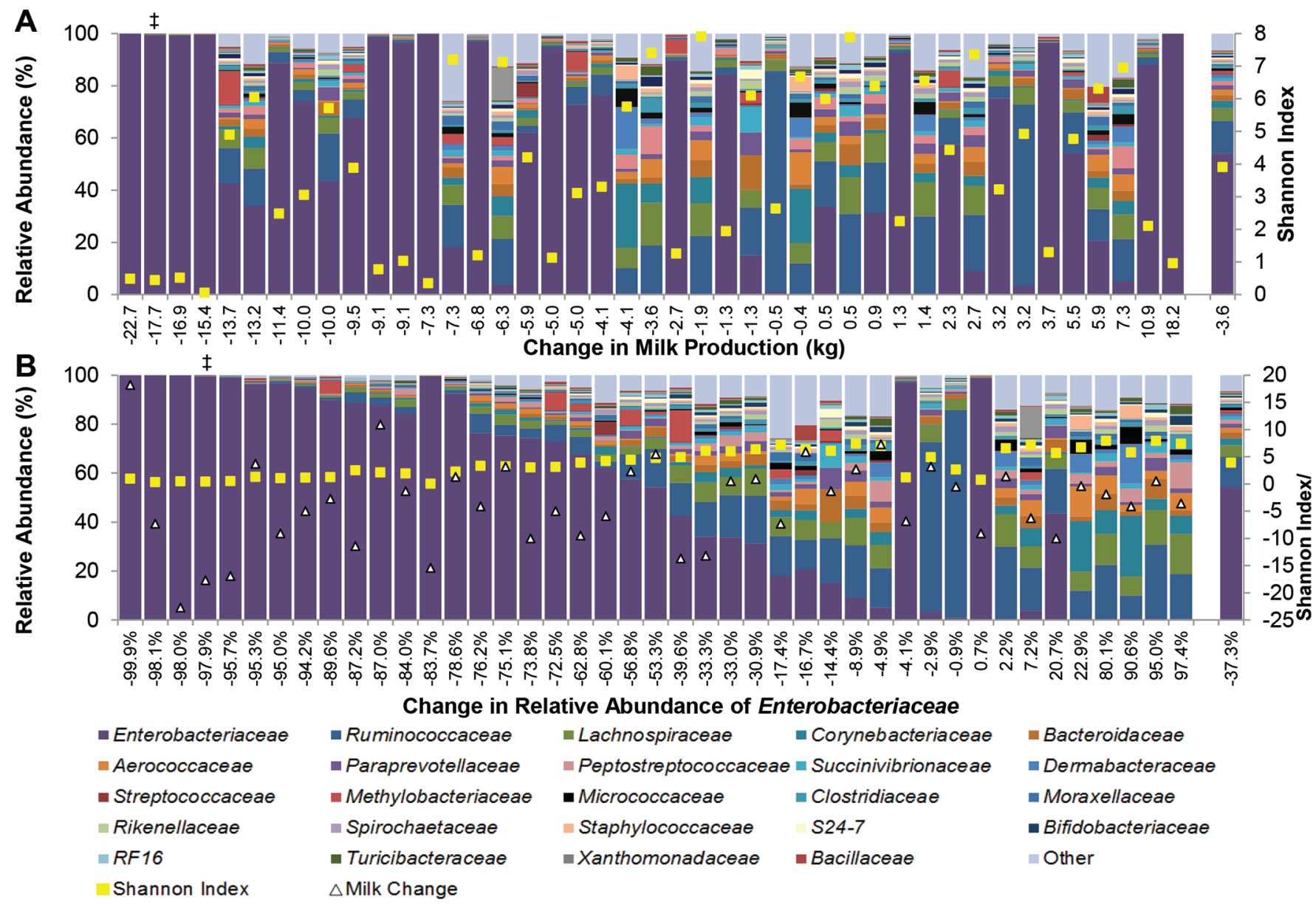

Figure 1. Investigating the relationship between metagenomic profile at enrollment and milk production outcomes. The top 25 most abundant families in individual cows $(\mathrm{n}=43)$ experiencing mild to moderate clinical mastitis characterized on aerobic culture as Escherichia coli (final column is mean of all cows). (A) The relationship of the microbial profile to the Shannon index (yellow squares) plotted by the change in milk production $(\mathrm{kg})$ between the test day before and after the mastitis event (x-axis). (B) The relationship of the microbial profile to the Shannon index (yellow squares) and change in milk production (white triangles) plotted by the change in relative abundance of Enterobacteriaceae between enrollment and follow-up samples (x-axis; $15 \mathrm{~d}$ after mastitis event). $\ddagger$ Cow did not survive in the herd $>60 \mathrm{~d}$.

tococcaceae $($ mean $=1.5 \% \mathrm{SE}=0.3 \%)$, Succinivibrionaceae $($ mean $=1.3 \%, \mathrm{SE}=0.3 \%)$, and Dermabacteraceae $($ mean $=1.1 \%, \mathrm{SE}=0.4 \%)$. The average reduction in relative abundance of Enterobacteriaceae between the enrollment and follow-up sample was $40.4 \%$ (SE $=7.8 \%$ ). Detailed information on bacterial profile per study animal is shown in Figures 1 and 2.

The most abundant families in the enrollment samples that were culture-negative were Ruminococcaceae $($ mean $=31.4 \%, \mathrm{SE}=4.5 \%)$, Streptococcaceae (mean $=11.7 \% ; \mathrm{SE}=4.5 \%)$, Lachnospiraceae $(6.9 \%, \mathrm{SE}=$ $0.8 \%)$, Corynebacteriaceae $($ mean $=6.6 \% ; \mathrm{SE}=2.6 \%)$, Bacteroidaceae $($ mean $=3.6 \%, \mathrm{SE}=0.4 \%)$, Moraxellaceae $($ mean $=1.4 \%, \mathrm{SE}=0.6 \%)$, Enterobacteriaceae $($ mean $=2.9 \%, \mathrm{SE}=2.0 \%)$, Bacillaceae (mean $=2.2 \% ; \mathrm{SE}=1.0 \%)$, Planococcaceae $($ mean $=2.4 \%$, $\mathrm{SE}=2.1 \%$ ), and Paraprevotellaceae (mean $=2.7 \%$, $\mathrm{SE}=0.3 \%)$. Nine quarters had $>25 \%$ abundance of a taxonomic family that includes species associated with major or minor mastitis-causing pathogens. These animals had profiles dominated by Streptococcaceae $(\mathrm{n}=$ 4: $84.0 \% ; 71.6 \%, 86.9 \%, 99.9 \%$ ), Enterobacteriaceae (n $=1: 72.5 \%)$, Corynebacteriaceae $(\mathrm{n}=2: 42.8 \%, 86.7 \%)$, Staphylococcaceae ( $\mathrm{n}=1: 38.3 \%$ ), and Clostridiaceae ( $\mathrm{n}$ $=1: 86.0 \%$ ). Two quarters had $>25 \%$ abundance of a taxonomic family not currently documented to include mastitis-causing pathogens: Planococcaceae (75.6\%) and Methylobacteriaceae (72.4\%). Detailed information on bacterial profile per study animal is shown in Figures 3 and 4 .

\section{Alpha-Diversity: Associations with Outcomes for E. coli-Positive Quarters}

Survival data were dichotomized into cows surviving in the herd $60 \mathrm{~d}$ postmastitis event, and those that 
did not. Only one cow $(2.0 \%)$ did not remain in the herd. As this sample number was not ideal for statistical comparisons of microbiome data, analysis was not performed for survival in the herd, however, the profile of this quarter is indicated with a symbol in Figures 1 and 2 .

Milk production change was normally distributed with a mean drop in milk production for culture-positive E. coli samples ( $\mathrm{n}=43$ with full data) of $3.6 \mathrm{~kg}$ $(\mathrm{SE}=1.2 \mathrm{~kg})$. A relationship was observed between the measure of $\alpha$-diversity and changes in milk production. As Shannon index increased (Spearman $\mathrm{r}=0.36, P=$ 0.02 ), production loss decreased (Figure 1A). When the outcome was dichotomized into cows that dropped in milk production by more than $2.2 \mathrm{~kg}$ and those that did not, the difference in Shannon index was 1.7. Cows that dropped in milk production had a mean index of 3.1
$(\mathrm{SE}=0.5)$; those that did not had a mean index of 4.8 $(\mathrm{SE}=0.5 ; P=0.02 ;$ Figure $5 \mathrm{~A})$. Likely associated with these differences is the relative abundance of Enterobacteriaceae in the enrollment samples, which was $38.4 \%$ $(\mathrm{SE}=9.0 \%)$ for cows that did not experience a drop in milk production and $67.8 \%(\mathrm{SE}=7.0 \%)$ for cows that did $(P=0.01$; Figures $1 \mathrm{~B}$ and $6 \mathrm{~A})$. When both the initial relative abundance of Enterobacteriaceae and change in milk production are used as parameters in linear regression to predict Shannon index, only Enterobacteriaceae $(P<0.001)$ remained important in the model. Despite these relationships, no statistical difference was observed between the cows that experienced a milk drop and those that did not when assessing the change in relative abundance of Enterobacteriaceae between the enrollment and follow-up samples $(P=0.17$; Figures $1 \mathrm{~B}$ and $6 \mathrm{C})$.
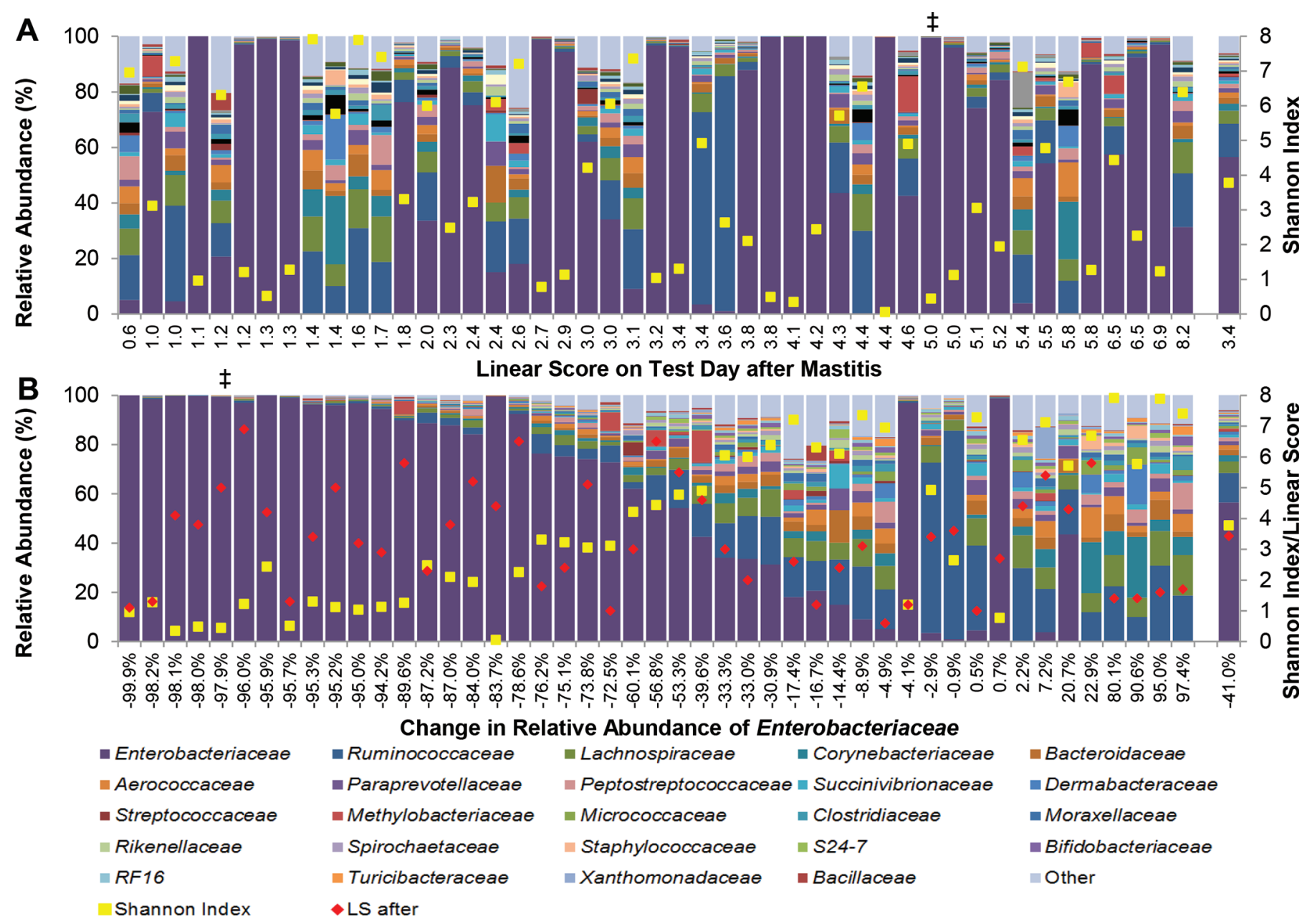

Figure 2. Investigating the relationship between metagenomic profile at enrollment and linear score (LS) outcomes. The top 25 most abundant families in individual cows $(\mathrm{n}=47)$ experiencing mild to moderate clinical mastitis characterized on aerobic culture as Escherichia coli

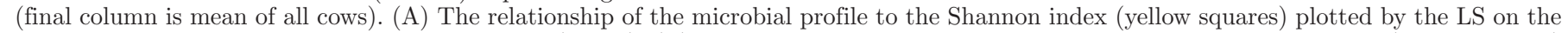
DHIA test day 8 to $43 \mathrm{~d}$ after the mastitis event (x-axis). (B) The relationship of the microbial profile to the Shannon index (yellow squares)

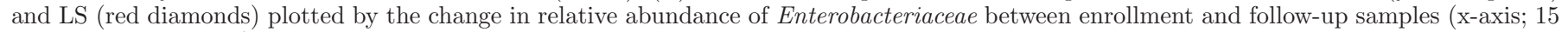
$\mathrm{d}$ after mastitis event). $\ddagger$ Cow did not survive in the herd $>60 \mathrm{~d}$. 
Linear score at next test was normally distributed with a mean of 3.4 and a SE of $0.3(\mathrm{n}=47)$. The relationship between the measure of $\alpha$-diversity and postmastitis LS was not statistically important (Spearman $\mathrm{r}=-0.18, P=0.23$; Figure $2 \mathrm{~A})$. When the outcome was dichotomized into cows that had a LS $\geq 4.0$ (SCC $\geq 200,000$ cells $/ \mathrm{mL}$ ) or LS $<4.0$ (SCC $<200,000$ cells/ $\mathrm{mL}$ ), the difference in Shannon index was 0.6; cows in the lower LS group had a mean Shannon index of $4.0(\mathrm{SE}=0.5)$, those in the higher group had a mean of 3.4 ( $\mathrm{SE}=0.6 ; P=0.31$; Figure $5 \mathrm{~B}$ ). Unlike the milk production outcome, the relative abundance of Enterobacteriaceae in the enrollment samples was not associated with the LS outcome $(P=0.32$; Figures 2B and $6 \mathrm{~B}$ ). No statistical difference was observed between the cows that experienced a LS $<4.0$ and those that did not when assessing the change in relative abundance of Enterobacteriaceae between the enrollment and followup samples $(P=0.32$; Figures $2 \mathrm{~B}$ and $6 \mathrm{D})$.

Also associated with $\alpha$-diversity and independent of outcome was the relative abundance of Enterobacteriaceae in the enrollment sample $(\mathrm{n}=50)$. As relative abundance increased, the Shannon index decreased (Spearman $\mathrm{r}=-0.91, P<0.0001$ ). This relationship was also present when comparing the linear correlation between change in relative abundance of Enterobacteriaceae between enrollment and follow-up samples and the Shannon index of the enrollment samples (Spearman $\mathrm{r}=0.79, P<0.0001)$.

The difference in $\alpha$-diversity between enrollment and follow-up samples for E. coli-positive cows $(\mathrm{n}=50)$ was also investigated. Shannon diversity was statisti-
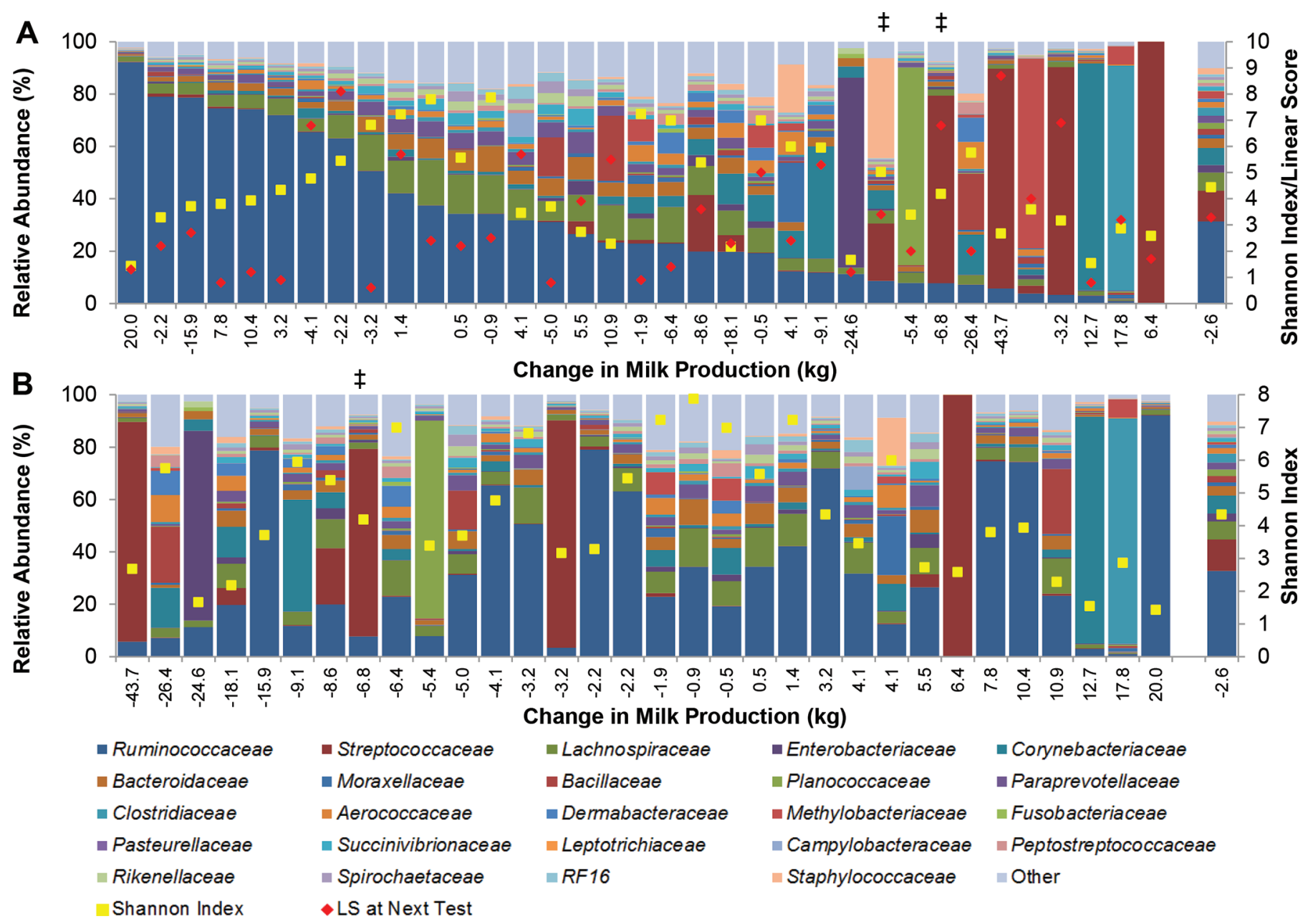

Figure 3. Investigating the relationship between metagenomic profile at enrollment and milk production outcomes for individual cows experiencing mild to moderate clinical mastitis and negative aerobic culture results. Final column is mean of all cows. (A) Relationships of the microbial profile to linear score (LS) at next test (red triangles), the Shannon index (yellow squares), and change in milk production (x-axis) between the test dates before and after the mastitis event plotted by the relative abundance of Ruminococcaceae for all cows $(\mathrm{n}=35)$ in the data set. Three cows experienced mastitis in early lactation and did not have initial milk production data. (B) Relationships of the microbial profile to the Shannon index and increasing positive milk production changes $(\mathrm{n}=32)$. $\ddagger$ Cows that did not survive in the herd $>60 \mathrm{~d}$. 
cally different between the sample types (enrollment $=3.8, \mathrm{SE}=0.3 ;$ follow-up $=5.1, \mathrm{SE}=0.3, P=0.01$; Figure $5 \mathrm{C})$.

\section{Beta-Diversity: Associations with Outcomes for E. coli-Positive Quarters}

Test statistics and $P$-values for $\beta$-diversity comparisons can be found in Table 2. The relative abundance of the family Enterobacteriaceae, as also noted in the $\alpha$-diversity comparisons, was the main driver of the variation in UniFrac distances (Figure 7A) in samples from E. coli-positive cows. A difference in the milk microbiome was detected between cows that did and did not experience a drop in milk production of $>2.2$ $\mathrm{kg}$ (permutational ANOVA unweighted $P=0.03$, weighted $P=0.01$ ). This is corroborated by the ANOSIM test $(P=0.05$; Figure $7 \mathrm{~B})$, and by visualization of principal coordinate analysis biplots in which cows not experiencing milk production drops are aggregated to the left side of the graph. Several highly influential samples from cows that experienced a drop in milk production $(\mathrm{n}=5)$ might be driving this difference. These samples each had $>99 \%$ abundance of Enterobacteriaceae and accounted for 5 out of 6 of the samples with $>99 \%$ abundance; 1 sample with high abundance of Enterobacteriaceae was contributed by a cow that did not experience a drop in milk production. Analysis of composition of the microbiome identified 1 OTU that differed statistically between groups, assigned to the phyla Proteobacteria. No differences were found at the family level.

\section{Enrollment Samples: Culture-Negative Quarters}

The subset of cows chosen from the larger study for metagenomic analysis of negative culture results $(\mathrm{n}=$ 35) had no previous cases of mastitis in the current lactation, nor were they treated with intramammary antimicrobials. The mean and median number of DIM at the time of the mastitis event were both $108 \mathrm{~d}$ (SE $=11.7$ ). Mastitis events were distributed across each lactation category as follows: $25.7 \%$ first parity $(\mathrm{n}=$ 9), $20.0 \%$ second parity $(\mathrm{n}=7)$, and $54.3 \%$ third and greater parities $(n=19)$.

\section{Alpha-Diversity: Associations with Outcomes for Culture-Negative Quarters}

Survival data were dichotomized into cows surviving in the herd $60 \mathrm{~d}$ postmastitis event, and those that did not. Only 2 cows $(5.7 \%)$ did not remain in the herd. Because sample number was not ideal for statistical comparisons of microbiome data, analysis was not performed for survival in the herd.

Milk production change was normally distributed with a mean drop in milk production for culture-negative samples of $2.4 \mathrm{~kg}(\mathrm{SE}=2.3 \mathrm{~kg})$. No statistical relationship was observed between the measures of $\alpha$-diversity and changes in milk production (Spearman $\mathrm{r}=-0.18$,

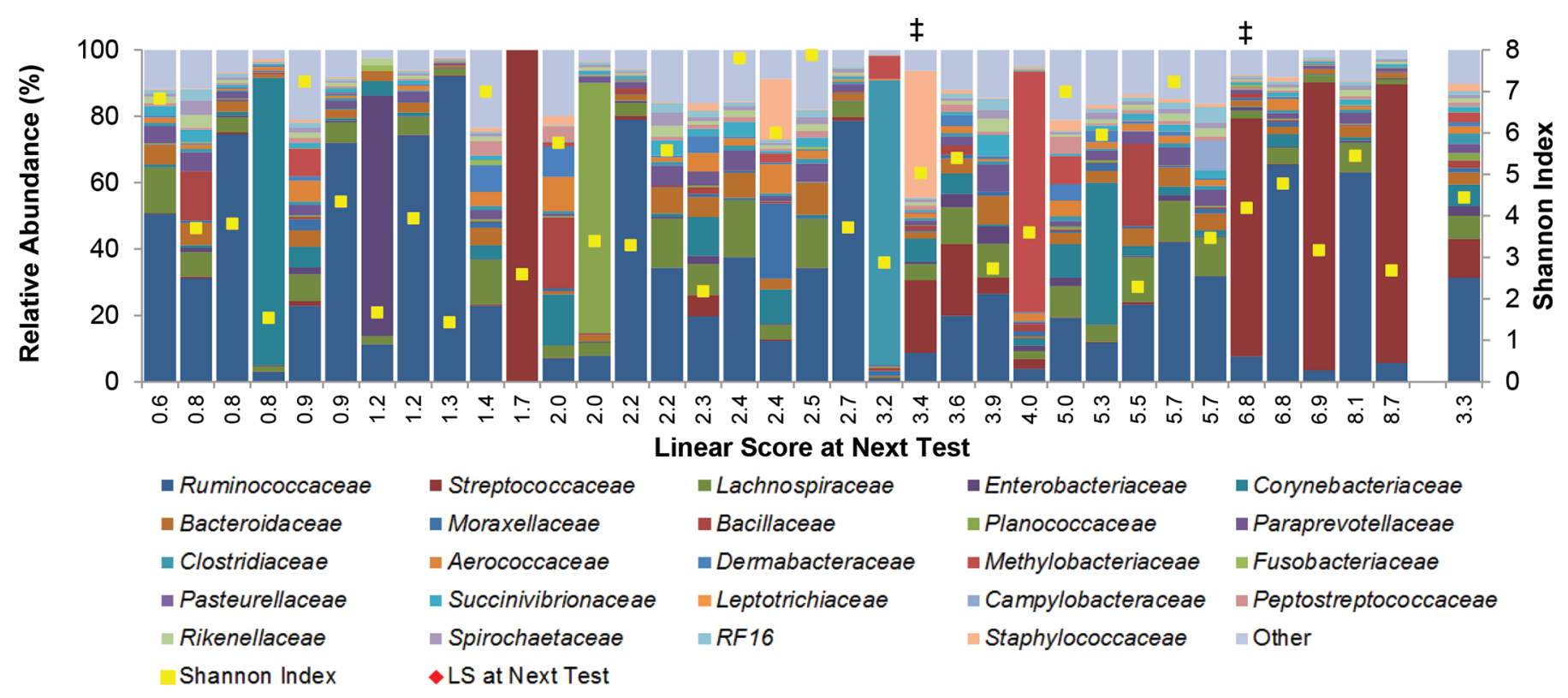

Figure 4. Investigating the relationship between metagenomic profile at enrollment, Shannon index, and linear score (LS) outcomes for

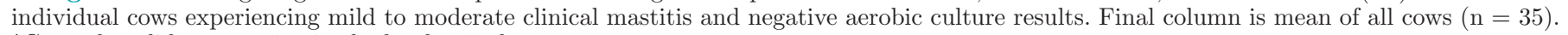
$\ddagger$ Cows that did not survive in the herd $>60 \mathrm{~d}$. 
A

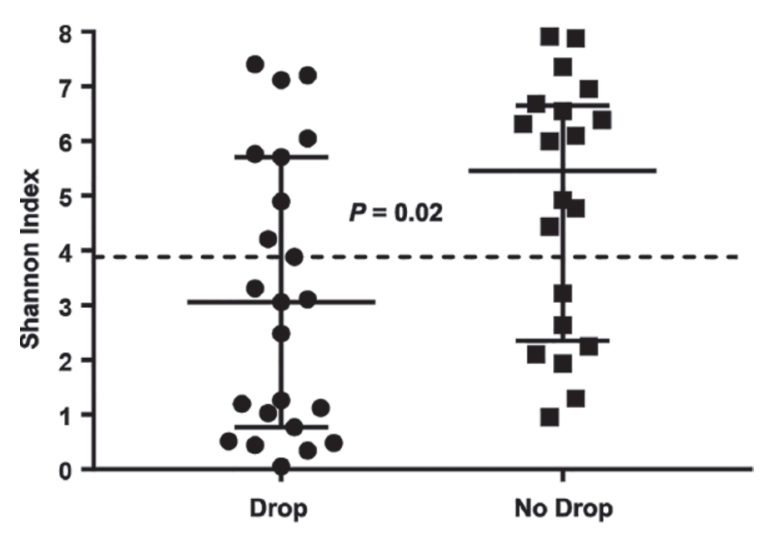

B

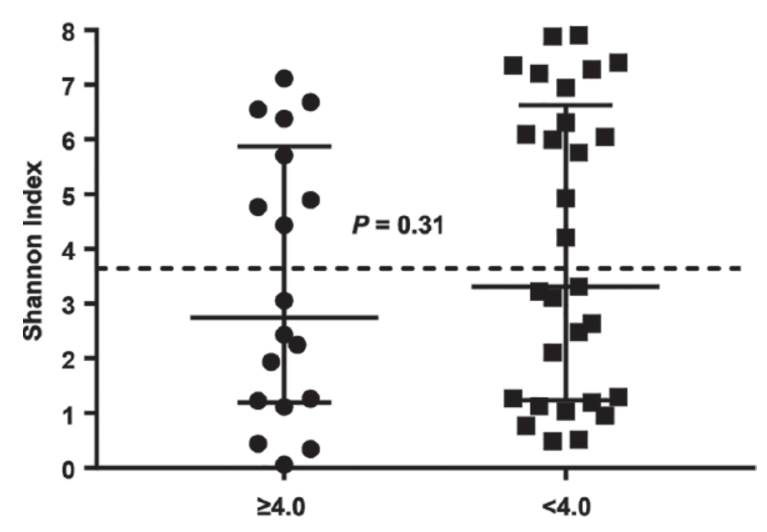

C

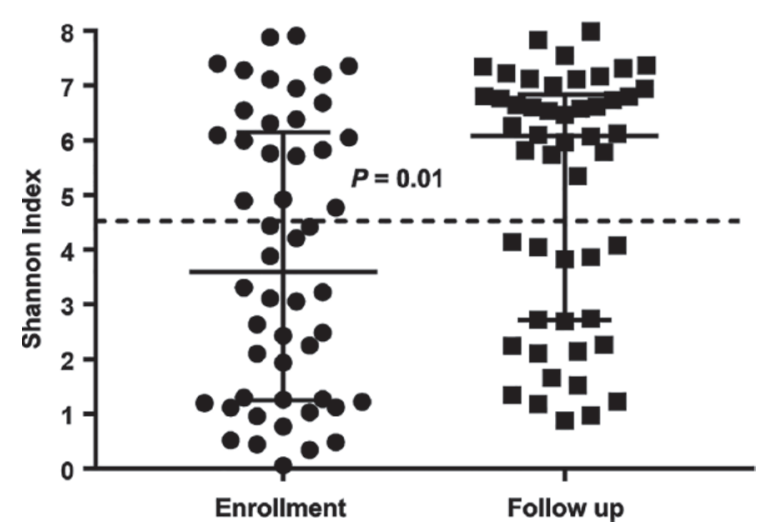

Figure 5. Scatterplots investigating the relationship between $\alpha$-diversity (Shannon index) of milk samples and outcomes for cows experiencing mild to moderate clinical mastitis characterized on aerobic culture as Escherichia coli. (A) Shannon index comparison of enrollment samples when milk production was dichotomized into cows that decreased in production by $2.2 \mathrm{~kg}$ (Drop) or did not (No Drop) between the test day before mastitis and the test day after $(\mathrm{n}=43)$. (B) Shannon index comparison of enrollment samples when linear score was dichotomized into cows that had a postmastitis test-day linear score $\geq 4.0$ or $<4.0(\mathrm{n}=47)$. (C) Shannon index comparison of enrollment samples versus follow-up samples $(\mathrm{n}=50)$. Medians and quartiles represented; dotted line represents grand mean. Statistical testing with Kruskal-Wallis (A and B) and Wilcoxon (C).
$P=0.32$; Figure 3B). Results were similar when the outcome was dichotomized into cows that dropped in milk production by more than $2.2 \mathrm{~kg}$ and those that did not; the difference in Shannon index was 0.1 (cows that dropped in production $=4.3 \mathrm{SE}=0.5$; those that did not $=4.4, \mathrm{SE}=0.4 ; P=0.95$; Figure $8 \mathrm{~A}$ ).

Linear score at next test was normally distributed with a mean of 3.3 and SE of 0.4 . The relationship between the measures of $\alpha$-diversity and postmastitis LS was not statistically significant (Spearman $\mathrm{r}=0.04, P$ $=0.84 ;$ Figure 4$)$. When the outcome was dichotomized into cows that had a $\mathrm{LS} \geq 4.0$ or $\mathrm{LS}<4.0$, the difference in Shannon index was 0.1 ; cows in the lower LS group had a mean Shannon index of $4.4(\mathrm{SE}=0.6)$ and those in the higher group had a mean of $4.5(\mathrm{SE}=0.4 ; P=$ 0.90; Figure 8B).

Also explored was the relative abundance of Ruminococcaceae and Shannon index, as milk from healthy cows has been documented to have comparatively larger relative abundances of this family (Falentin et al., 2016; Ganda et al., 2017; Lima et al., 2018). However, a relationship between the 2 parameters was not statistically significant (Spearman $\mathrm{r}=0.24, P=0.17$ ). The relative abundance of Ruminococcaceae was also not associated with a linear milk production change or the dichotomous milk drop outcome (linear: $\mathrm{r}=0.27, P$ $=0.26$; dichotomous: cows that dropped in production $=24 \%, \mathrm{SE}=0.06$, those that did not $=39 \%, \mathrm{SE}=$ $0.07, P=0.13)$. Linear score analysis produced similar findings, though abundances of Ruminococcaceae were also numerically higher for those cows that did not experience negative outcomes (linear: $\mathrm{r}=-0.19, P=$ 0.26 ; dichotomous: $\mathrm{LS} \geq 4.0$ mean $=25.2 \%$, LS $<4.0$ mean $=34.2 \%, P=0.37)$.

\section{Beta-Diversity: Associations with Outcomes for Culture-Negative Quarters}

Test statistics and $P$-values for $\beta$-diversity comparisons can be found in Table 2. No statistical differences were found for comparisons made between cows experiencing positive and negative outcomes within the data set of culture-negative cows. Analysis of composition of microbiomes was explored, but no differential OTU were present at any taxonomic level when comparing outcomes.

\section{DISCUSSION}

Reduced microbial diversity has been associated with several human diseases such as inflammatory bowel disease and obesity (Ley et al., 2006; Turnbaugh et al., 2009). Similarly, primiparous cows that would go on to experience mastitis within the first $30 \mathrm{~d}$ postpartum 
Table 2. Beta-diversity statistical comparisons between metagenomic profiles of cows with negative versus positive outcomes for cows experiencing mild to moderate clinical mastitis characterized as Escherichia coli or negative on aerobic culture

\begin{tabular}{|c|c|c|c|c|c|}
\hline \multirow[b]{2}{*}{ Outcome } & \multirow[b]{2}{*}{ No. } & \multicolumn{2}{|c|}{ Unweighted UniFrac } & \multicolumn{2}{|c|}{ Weighted UniFrac } \\
\hline & & Test statistic & $P$-value & Test statistic & $P$-value \\
\hline E. coli on culture & 43 & 1.97 & 0.03 & 4.11 & 0.01 \\
\hline Negative on culture & 32 & 0.85 & 0.70 & 0.97 & 0.38 \\
\hline \multicolumn{6}{|c|}{ Linear score $<4.0$ versus $\geq 4.0$} \\
\hline E. coli on culture & 47 & 0.92 & 0.50 & 0.44 & 0.76 \\
\hline
\end{tabular}

${ }^{1}$ Drop in milk production dichotomized into $\leq 2.2$ or $>2.2 \mathrm{~kg}$.

had colostrum with a lower diversity index than those that did not (Lima et al., 2017). Using these concepts, we wished to determine if there is a characteristic mastitis microbiome associated with LS or changes in milk production, in the absence of treatment. This study applied 16S metagenomic characterization of culture-

A

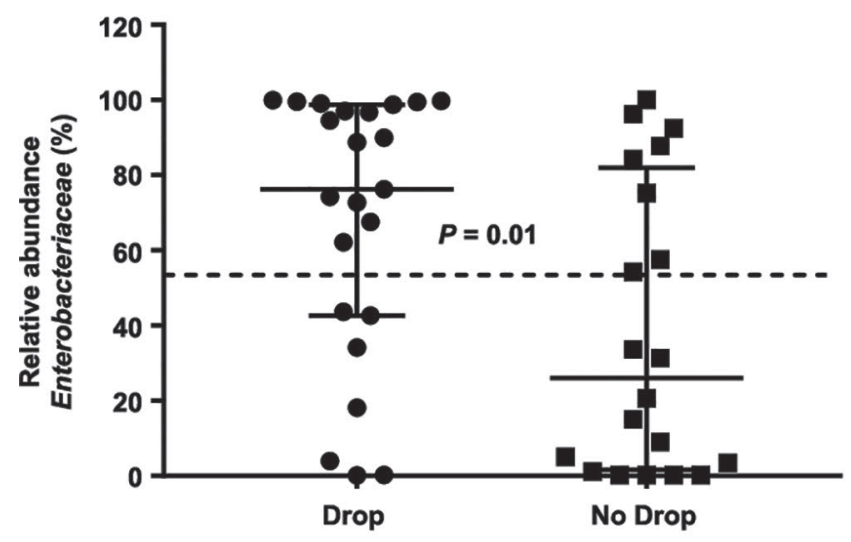

C

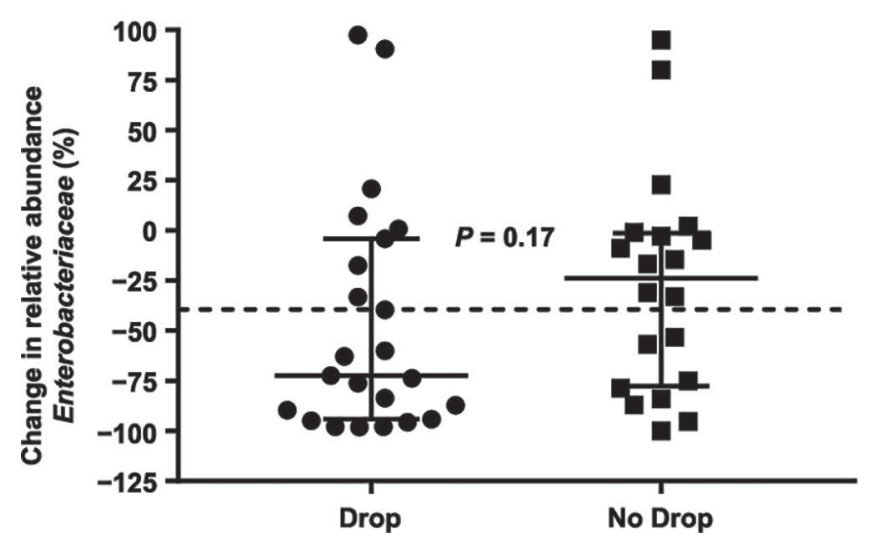

negative and E. coli-positive nonsevere mastitis cases for this purpose. When milk production changes and postmastitis LS were investigated for E. coli-positive cows, associations between $\alpha$ - and $\beta$-diversity measurements, milk production changes, and initial abundance of Enterobacteriaceae were present. No associations
B

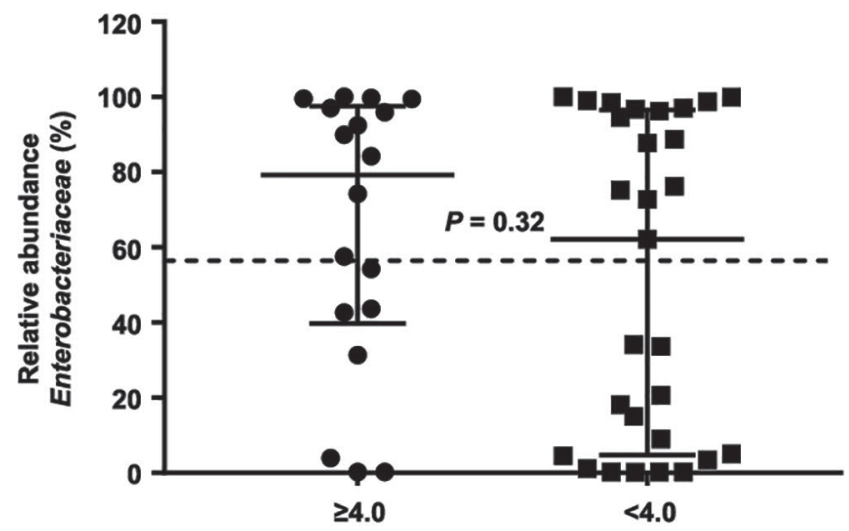

D

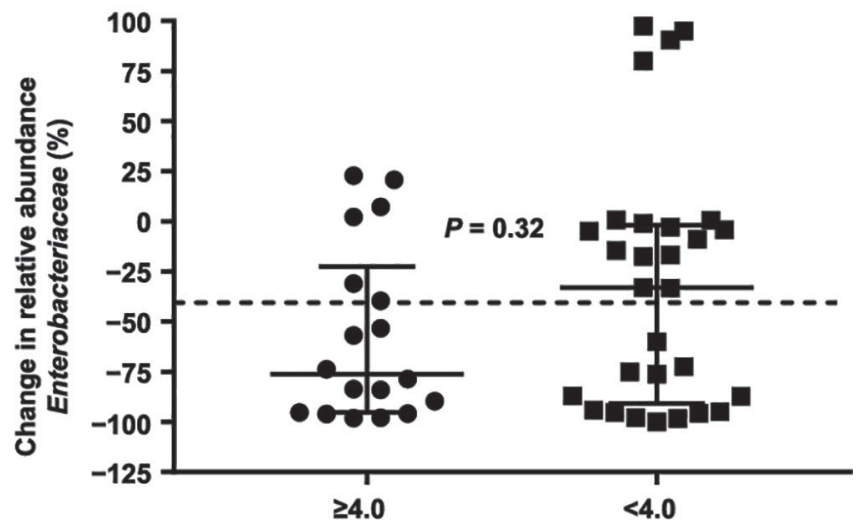

Figure 6. Scatterplots investigating the relationship between relative abundance of Enterobacteriaceae (A, B) and change in relative abundance of Enterobacteriaceae between enrollment and follow-up samples (C, D) for the following outcomes: drop in milk production ( $\mathrm{n}=43$; A, C) or postmastitis linear score $<4.0$ or $\geq 4.0(\mathrm{n}=47$; B, D). Medians and quartiles are represented; dotted line represents grand mean. Statistical testing with Kruskal-Wallis (A and B) and Wilcoxon (C and D). 
were found for $\alpha$ - and $\beta$-diversity measurements and outcomes for culture-negative cows. No set of microorganisms in E. coli-positive or culture-negative samples was associated with the outcomes explored.

Alpha- and $\beta$-diversities of the $E$. coli-positive samples were associated with relative abundance of Enterobacteriaceae and milk production changes. The larger relative abundance of Enterobacteriaceae in samples from cows that experienced larger drops in milk production is perhaps reflective of a higher relative abundance of E. coli, though the current taxonomic analysis did not classify organisms to the species level. If relative abundance is used as a proxy for bacterial numbers, which is often true when the pathogen identified is the etiologic cause, the association between diversity measurements and milk production changes found is likely due a greater concentration of E. coli and subsequently LPS in the mammary gland. This can be ascribed to the knowledge that the outcome and severity of $E$. coli mastitis is mainly attributed to environmental and immune factors in response to LPS, rather than virulence of the E. coli strain (Burvenich et al., 2003; Mehrzad et al., 2008). The authors speculate that associations were found for changes in milk production, but not for postmastitis LS, due to the transient nature of the organism. Initial growth of $E$. coli is decelerated by a quick spike in somatic cells in the milk (Hill, 1981), and while LS recovers, perhaps secretory epithelial damage in the gland undergoes a more delayed resolution, if any. Further investigation using quantitative PCR, LPS bioassays, or biopsy would provide answers to these hypotheses.

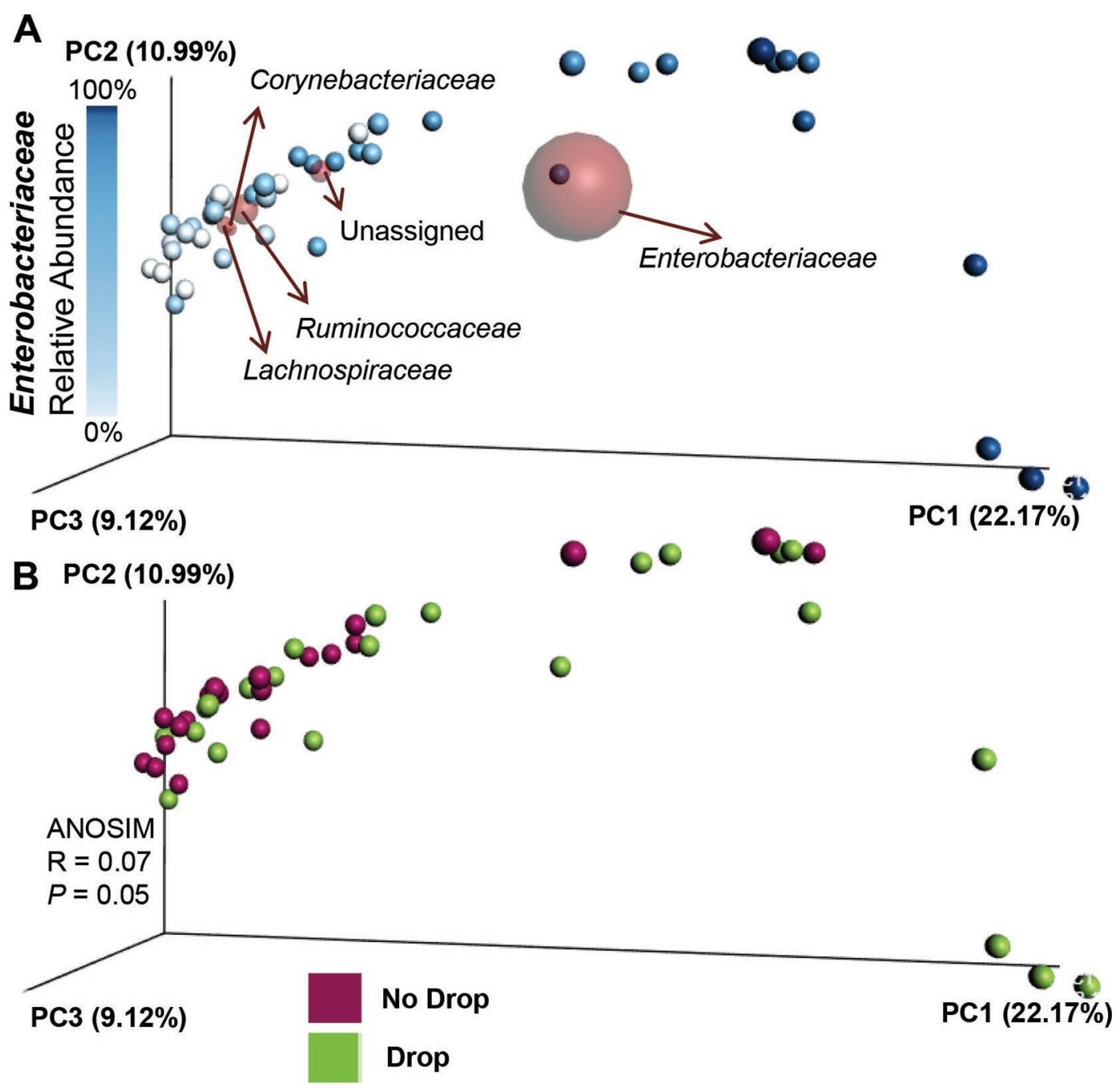

Figure 7. Biplots depicting use of weighted UniFrac distances for principal coordinate (PC) analysis of Escherichia coli culture-positive samples $(\mathrm{n}=43)$ and $(\mathrm{A})$ the coordinates of the 5 most abundant family-level taxa (red spheres) in the context of relative abundance of Enterobacteriaceae. (B) Relationship of the same samples comparing samples of cows that dropped in milk production (Drop; $>2.2 \mathrm{~kg}$ ), and those that did not (No Drop) in analysis of similarity (ANOSIM). 
A

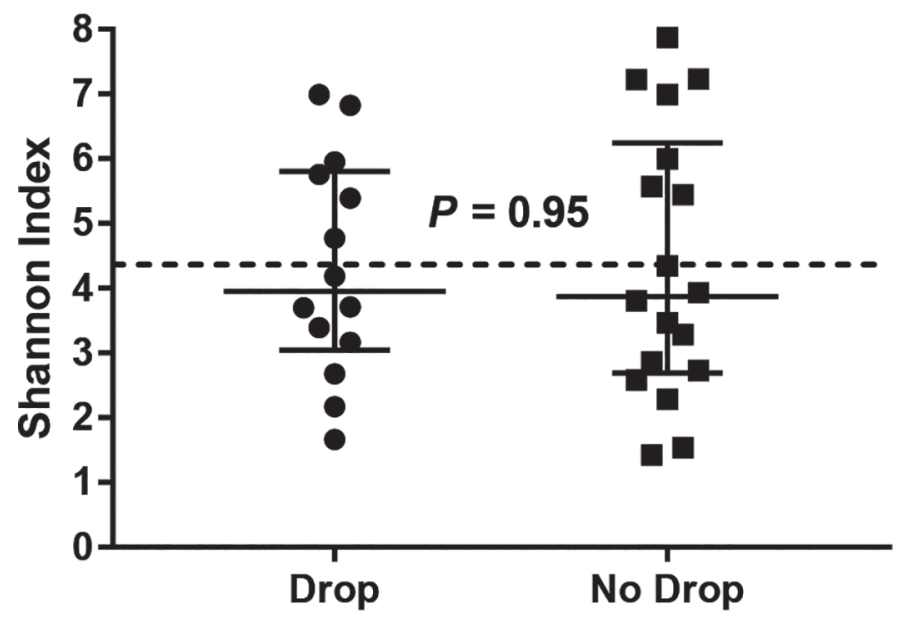

B

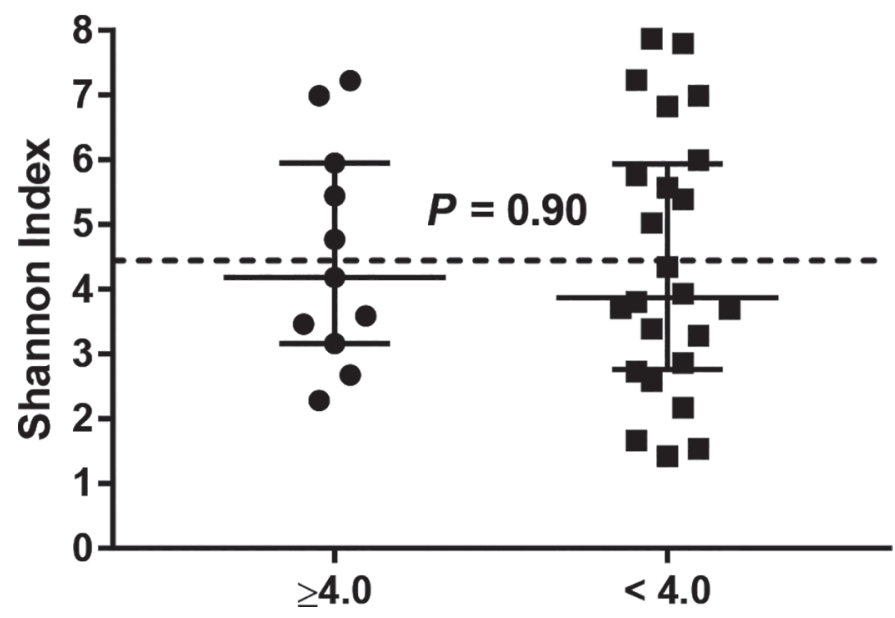

Figure 8. Scatterplots investigating the relationship between $\alpha$ diversity (Shannon index) and outcomes for cows experiencing mild to moderate clinical mastitis characterized on aerobic culture as negative. (A) Shannon index comparison when milk production was dichotomized into cows that had a decrease in production by $2.2 \mathrm{~kg}$ (Drop) and those that did not (No Drop) between the test day before mastitis and the test day after $(\mathrm{n}=32)$. (B) Shannon index comparison when linear score was dichotomized into cows that had a postmastitis test-day linear score $\geq 4.0$ or $<4.0(\mathrm{n}=35)$. Median and quartiles are represented; dotted line represents grand mean. Statistical testing with Kruskal-Wallis.

Upon analysis of composition of microbiomes, the phylum Proteobacteria was differentially abundant between the $E$. coli samples from cows that experienced a drop in production and from those that did not. Proteobacteria were also higher in abundance in E. coli-positive quarters compared with healthy quarters in Ganda et al. (2016), and were driven by greater abundances of Enterobacteriaceae, as observed in the current study. Other investigators have observed that drops in milk production were highest and most persistent for cows with E. coli infections (Gröhn et al., 2004; Schukken et al., 2009), which agree with our findings for these quarters. Also, clinical cure was statistically different between cows having higher versus lower abundances of Enterobacteriaceae in Ganda et al. (2016), indicating that clinical outcomes are affected by this measure.

Despite the presence of only E. coli on aerobic culture or the absence of pathogens for the culture-negative samples, metagenomic analysis of milk from these quarters revealed the presence of a large diversity of taxonomic families. This is consistent with previous characterization of mastitic and healthy human and bovine milk microbiomes and also supports the idea of an endogenous entero-mammary pathway, as many families present in the gastrointestinal tract such as Ruminococcaceae, Clostridiaceae, Peptostreptococcaceae, and Lachnospiraceae were present in the current study. This agrees with findings from conventionally sampled quarters as well as samples retrieved via cannula (Jost et al., 2014; Young et al., 2015; Addis et al., 2016; Ganda et al., 2016). These taxonomic families are also found in fecal matter from cattle; contamination of samples or entry of these organisms into the udder via the teat canal is possible (Young et al., 2015).

Using quantitative methods, groups have shown that despite the vast representation of different microbial species in both healthy and mastitic milk samples, mastitic samples contain statistically larger bacterial loads or higher overall DNA concentrations than their healthy counterparts (Kuehn et al., 2013; Ganda et al., 2016). Additionally, negative correlations between the Shannon index and bacterial load have been described, indicating that when overall microbial concentration increases, microbial diversity is decreased (Bonsaglia et al., 2017). This can be observed for the Shannon indices of the mastitic quarters in the current study, which were 3.5 for $E$. coli-positive quarters and 4.5 for culture-negative quarters. Values are similar to those documented for mastitic quarters and much lower than values observed in healthy quarters, which range from 7.0 to 9.0 (Oikonomou et al., 2014; Ganda et al., 2016; Rodrigues et al., 2017). In the 15-d follow-up samples, quarters in the current study reached a mean value of 5.1; in the Ganda et al. (2016) study, mean values for E. coli and culture-negative mastitic quarters at $14 \mathrm{~d}$ were approximately 6.5 . This could be due to a greater decrease in relative abundance of Enterobacteriaceae from d 1 to 14 (reduction from 62.6 to 9.7\%) in Ganda et al. (2016) as compared with our findings (reduction from 55.7 to $15.2 \%$ ).

Although colonies were absent upon aerobic culture of the follow-up samples, a presence of genomic material belonging to the family Enterobacteriaceae (9.7\%) 
remained. This finding could be reflective of the low but acceptable detection limit of culture for an IMI in the current study, which was 1,000 colonies/mL (Dohoo et al., 2011). It should be noted that the starting material for $16 \mathrm{~S}$ analysis, which also includes an amplification step, is more than 100 times that of traditional culture $(2 \mathrm{~mL})$. More likely, free ribosomal RNA from nonviable organisms could produce these findings. Because the risk for bacteriological cure in the current study was $100 \%$, the differences between the microbiomes of quarters that did and did not cure could not be evaluated. Regardless, our high spontaneous cure rate agrees with Ganda et al. (2016) who found that $85 \%$ of nontreated and $80 \%$ of treated E. coli-positive quarters experienced bacteriological cure. Roberson et al. (2004) also found that $85 \%$ of $E$. coli cases $(17 / 20)$ were cured bacteriologically by $7 \mathrm{~d}$, regardless of treatment.

Bacteriological cure was not assessed for culture-negative quarters as no pathogen was isolated on aerobic culture. Indeed, a major finding in this study was the inability to identify a potentially causative taxonomic family in the microbial profiles of 24 of the 35 samples. This is similar to results outlined in Oikonomou et al. (2014) and Ganda et al. (2016): none of the culturenegative clinical quarters contained a taxonomic family representing over $25 \%$ relative abundance. Our findings are also similar to those described in Kuehn et al. (2013), where no genus represented greater than $25 \%$ of the microbiome in 9 out of 10 culture-negative CM samples. Possibilities for samples with these characteristics are nonbacterial causes of mastitis such as viral origins or injury (Wellenberg et al., 2002; Tolosa et al., 2015); the re-establishment of the endogenous microbiome subsequent to bacterial clearance but with continued local inflammatory changes; or the establishment of an altered, more susceptible but diverse microbiome as suggested by the findings by Falentin et al. (2016). In the latter study, quarters with previous mastitis events had strikingly different microbiomes than healthy quarters, even far from the event.

Nine culture-negative quarters were dominated by one taxonomic family that includes species associated with major or minor mastitis-causing pathogens. If these pathogens were the primary cause of mastitis, they would likely have been apparent by culture if the bacteria were at higher concentrations, or more importantly, if the bacteria were still viable - a characteristic that cannot be assessed through sequencing methods. Therefore, the presence of a dominant family on $16 \mathrm{~S}$ analysis of culture-negative samples may be indicative of a primary infection that has spontaneously resolved. The dominant families identified in 7 of the samples (Streptococcaceae, Corynebacteriaceae, and Staphylococcaceae) have also been identified in healthy human and bovine milk, suggesting that they are a normal part of the milk microbiota (Hunt et al., 2011; Ward et al., 2013; Ganda et al., 2016; Bonsaglia et al., 2017). Therefore, again, we cannot rule out a dysbacteriosis or disruption of the normal microbiota as an alternative to, or an addition to, a primary infection. Alternatively, members of the Staphylococcaceae and Corynebacteriaceae families can be commensals habituating teat skin, which, taking into account our procedure for collecting milk, might be contaminants or might support the overlap of the microbiota of the environments (VerdierMetz et al., 2012; Kuehn et al., 2013). Indeed, the variety of bacterial taxa and respective relative abundances observed is dependent on sample collection method and timing, bedding type, and molecular techniques (Falentin et al., 2016; Metzger et al., 2018). Recent research indicates that samples removed directly from the gland cistern using a needle contain fewer and less diverse communities of bacterial species as compared with conventional samples (Hiitiö et al., 2016; Metzger et al., 2018). Samples retrieved by stripping milk through the teat canal into a collection vial can still be used to generate data, enabling one to make comparisons between quarters in an individual study, assuming they were taken in a similar manner. Differences observed between trials are likely due to a variety of on-farm and laboratory methods.

Characterization of the microbiomes of culturenegative samples infrequently identified a dominant pathogen. Likewise, no differential taxa or group of pathogens was associated with LS or milk production outcomes. Additionally, $\alpha$ - and $\beta$-diversity measures within and between outcome groups were similar. The inability to detect a pathogenic profile sheds light on previous findings from culture-based selective treatment protocols where authors showed no differences in several health and production outcomes between cows assigned to blanket intramammary therapy and cows assigned to selective treatment (Lago et al., 2011a,b; Vasquez et al., 2017; McDougall et al., 2018). For example, in Lago et al. (2011a,b), linear SCC, days to clinical cure, bacteriologic cure risk, new infection risk, treatment failure risk, and milk production were similar between untreated culture-negative cases and treated culture-negative cases as well as between untreated gram-negative cases and treated gram-negative cases. Not all outcomes investigated in Lago et al. (2011a,b) were explored for their relationship to the microbiome in the current study. Few cows with no-growth or $E$. coli-positive cultures experienced negative outcomes related to culling, clinical cure, or treatment failure; low sample numbers prevented the ability to assess these outcomes in the current study. Although inherently bacteriological cure risk cannot be evaluated for 
culture-negative cases, follow-up cultures would have allowed for exploration of new infection risk and the relationship to aspects of the mastitis microbiome, something that was not performed in the current study.

Perhaps no associations were present at the family level between culture-negative cows that experienced negative outcomes and those that experienced positive outcomes because the samples were similar to profiles of healthy quarters. The resilient nature of the milk microbiome was described by Ganda et al. (2016). In that study, differences were found between profiles of culture-negative mastitis samples versus healthy samples on d 0 when evaluating ANOSIM, but a clear separation in principal coordinate analysis ( $\beta$-diversity) was not observed. When comparing healthy to culturenegative mastitic quarters, shifts in the milk microbiome for several different phyla (Firmicutes, Bacteroidetes, Tenericutes, and Spirochaetes) were found in Ganda et al. (2016). At d 14, however, the profiles were indistinguishable. Evaluation on the phyla level was evaluated for culture-negative samples in the current study, but no differential phyla were found. The addition of more cows to the current study might have allowed the detection of differences in microbial profiles. With the advent of big data, there are no guidelines dictating or suggesting an appropriate sample size to ensure the ability to detect differences in microbiomes between multiple groups, given a specified level of type I error.

A limitation of our study design is the absence of healthy quarter samples or follow-up cultures from each affected quarter. Benefits exist for having a healthy quarter comparison because individuals can have diverse microbial profiles dependent on parity, stage of lactation, environment, or BW (Hunt et al., 2011; Cabrera-Rubio et al., 2016; Lima et al., 2017). Characterization of a healthy contralateral quarter or a postresolution sample might allow us to discriminate between a primary infection or a dysbacteriosis. From a healthy quarter comparison, Oultram et al. (2017) used a 2-fold increase in bacterial relative abundance to diagnose $80 \%$ of the potentially causative pathogens. Kuehn et al. (2013) also used a healthy quarter comparison to identify 7 differentially present genera in culture-negative mastitis samples versus healthy samples. If follow-up samples were available, similar techniques could have been used in the current study to determine whether certain bacteria in the culture-negative quarters were causative; healthy versus mastitic analysis would allow us to rule out the contribution of specific taxonomic families to negative outcomes. However, it is important to note that taxonomic profiles of quarters corresponding to the same animal are not necessarily more similar than those corresponding to different ani- mals, as described in a recent study by Falentin et al. (2016).

A statistically higher number of later lactation cows was present in the LS $\geq 4.0$ and milk drop groups versus the respective positive outcome groups for culture-negative quarters. This finding is well supported by research that shows that higher-parity cows experience greater effects on milk production during mastitis events, and are overall more susceptible to repeat mastitis events (Gröhn et al., 2004; Pinzón-Sánchez and Ruegg, 2011; Hiitiö et al., 2017). As microbiota can be more diverse for higher parity animals, a selection of cows from the same lactation may have provided a better comparison (Lima et al., 2017). Similarly, a shorter time period between the mastitis event and the next-test day was associated with the higher LS category. Therefore, cows in the data set that were allowed more time to recover from the mastitis event before data retrieval appeared to experience more positive outcomes. Collection of a test-day sample from the affected quarter at a standard number of days after the event would eliminate this bias. Ideally, to minimize bias associated with time between the mastitis event and test day data, and to best characterize the effects of microbiota on milk production and LS, daily milk weights and LS could be recorded. Despite discrepancies between demographics of the outcome groups, the results for comparisons of diversity measurements of pathogen profiles do not support the need to treat E. coli and culture-negative cases with currently available antibiotics. However, cow characteristics and historical LS should also be considered when making treatment decisions.

\section{CONCLUSIONS}

The current study presented an analysis of the milk microbiome of culture-negative and E. coli-positive CM quarters. Irrespective of metagenomic characteristics, many of the cases experienced positive outcomes without treatment. No pathogen profile in culture-negative cases was associated with LS or milk production outcomes. Relative abundance of Enterobacteriaceae was associated with greater losses in milk production between test days for cows that were experiencing nonsevere $E$. coli mastitis. However, no E. coli-positive cow cultured positive for this organism $15 \mathrm{~d}$ after the mastitis event. As dairies are more commonly using diagnostic tools to aid in treatment decisions, more research is needed for those cases that will not be treated, specifically for characterizing or confirming a dysbacteriosis and for exploring associations between the microbiome and additional outcomes. 


\section{ACKNOWLEDGMENTS}

The authors acknowledge the support of the employees of the farm in addition to Gregory Johnson (Dryden, NY). We thank Kerry Case (Quality Milk Production Services, Ithaca, NY) and Charles Tribley (Quality Milk Production Services, Cobleskill, NY) for assistance with sample retrieval and the couriers and veterinarians at Quality Milk Production Services (QMPS, Ithaca, NY) for correspondence with the farm and culture of the samples.

\section{REFERENCES}

Addis, M. F., A. Tanca, S. Uzzau, G. Oikonomou, R. C. Bicalho, and P. Moroni. 2016. The bovine milk microbiota: Insights and perspectives from -omics studies. Mol. Biosyst. 12:2359-2372. https:/ /doi.org/10.1039/c6mb00217j.

Ali, A. K. A., and G. E. Shook. 1980. An optimum transformation for somatic cell concentration in milk. J. Dairy Sci. 63:487-490. https: //doi.org/10.3168/jds.S0022-0302(80)82959-6.

Anderson, M. J. 2001. A new method for non-parametric multivariate analysis of variance. Austral Ecol. 26:32-46. https://doi.org/ 10.1111/j.1442-9993.2001.01070.pp.x.

Bonsaglia, E. C. R., M. S. Gomes, I. F. Canisso, Z. Zhou, S. F. Lima, V. L. M. Rall, G. Oikonomou, R. C. Bicalho, and F. S. Lima. 2017. Milk microbiome and bacterial load following dry cow therapy without antibiotics in dairy cows with healthy mammary gland. Sci. Rep. 7:8067. https://doi.org/10.1038/s41598-017-08790-5.

Burvenich, C., V. Van Merris, J. Mehrzad, A. Diez-Fraile, and L. Duchateau. 2003. Severity of $E$. coli mastitis is mainly determined by cow factors. Vet. Res. 34:521-564. https://doi.org/10.1051/vetres: 2003023.

Cabrera-Rubio, R., L. Mira-Pascual, A. Mira, and M. C. Collado. 2016. Impact of mode of delivery on the milk microbiota composition of healthy women. J. Dev. Orig. Health Dis. 7:54-60. https:// doi.org/10.1017/S2040174415001397.

Callahan, B. J., P. J. McMurdie, M. J. Rosen, A. W. Han, A. J. Johnson, and S. P. Holmes. 2016. DADA2: High-resolution sample inference from Illumina amplicon data. Nat. Methods 13:581-583. https://doi.org/10.1038/nmeth.3869.

Caporaso, J. G., K. Bittinger, F. D. Bushman, T. Z. DeSantis, G. L. Andersen, and R. Knight. 2010b. PyNAST: A flexible tool for aligning sequences to a template alignment. Bioinformatics 26:266-267. https://doi.org/10.1093/bioinformatics/btp636.

Caporaso, J. G., J. Kuczynski, J. Stombaugh, K. Bittinger, F. D. Bushman, E. K. Costello, N. Fierer, A. G. Peña, J. K. Goodrich, J. I. Gordon, G. A. Huttley, S. T. Kelley, D. Knights, J. E. Koenig, R. E. Ley, C. A. Lozupone, D. McDonald, B. D. Muegge, M. Pirrung, J. Reeder, J. R. Sevinsky, P. J. Turnbaugh, W. A. Walters, J. Widmann, T. Yatsunenko, J. Zaneveld, and R. Knight. 2010a. QIIME allows analysis of high-throughput community sequencing data. Nat. Methods 7:335-336. https://doi.org/10.1038/nmeth.f .303 .

Caporaso, J. G., C. L. Lauber, W. A. Walters, D. Berg-Lyons, J. Huntley, N. Fierer, S. M. Owens, J. Betley, L. Fraser, M. Bauer, N. Gormley, J. A. Gilbert, G. Smith, and R. Knight. 2012. Ultrahigh-throughput microbial community analysis on the Illumina HiSeq and MiSeq platforms. ISME J. 6:1621-1624. https://doi .org/10.1038/ismej.2012.8.

DeSantis, T. Z., P. Hugenholtz, N. Larsen, M. Rojas, E. L. Brodie, K. Keller, T. Huber, D. Dalevi, P. Hu, and G. L. Andersen. 2006. Greengenes, a chimera-checked $16 \mathrm{~S}$ rRNA gene database and workbench compatible with ARB. Appl. Environ. Microbiol. 72:5069-5072. https://doi.org/10.1128/AEM.03006-05.

Dohoo, I. R., and K. E. Leslie. 1991. Evaluation of changes in somatic cell counts as indicators of new intramammary infec- tions. Prev. Vet. Med. 10:225-237. https://doi.org/10.1016/0167 -5877(91)90006-N.

Dohoo, I. R., J. Smith, S. Andersen, D. F. Kelton, and S. Godden. 2011. Mastitis Research Workers Conference: Diagnosing intramammary infections: Evaluation of definitions based on a single milk sample. J. Dairy Sci. 94:250-261. https://doi.org/10.3168/jds.2010 -3559 .

Edgar, R. C. 2010. Search and clustering orders of magnitude faster than BLAST. Bioinformatics 26:2460-2461. https://doi.org/10 .1093/bioinformatics/btq461.

Falentin, H., L. Rault, A. Nicolas, D. S. Bouchard, J. Lassalas, P. Lamberton, J.-M. Aubry, P.-G. Marnet, Y. LeLoir, and S. Even. 2016. Bovine teat microbiome analysis revealed reduced alpha diversity and significant changes in taxonomic profiles in quarters with a history of mastitis. Front. Microbiol. 7:480. https://doi.org/ 10.3389/fmicb.2016.00480.

Fernández, L., S. Langa, V. Martín, A. Maldonado, E. Jimenéz, R. Martín, and J. M. Rodríguez. 2013. The human milk microbiota: Origin and potential roles in health and disease. Pharmacol. Res. 69:1-10. https://doi.org/10.1016/j.phrs.2012.09.001.

Ganda, E. K., R. S. Bisinotto, S. F. Lima, K. Kronauer, D. H. Decter, G. Oikonomou, Y. H. Schukken, and R. C. Bicalho. 2016. Longitudinal metagenomic profiling of bovine milk to assess the impact of intramammary treatment using a third-generation cephalosporin. Sci. Rep. 6:37565. https://doi.org/10.1038/srep37565.

Ganda, E. K., N. Gaeta, A. Sipka, B. Pomeroy, G. Oikonomou, Y. H. Schukken, and R. C. Bicalho. 2017. Normal milk microbiome is reestablished following experimental infection with Escherichia coli independent of intramammary antibiotic treatment with a thirdgeneration cephalosporin in bovines. Microbiome 5:74. https://doi .org/10.1186/s40168-017-0291-5.

Gilbert, J. A., F. Meyer, D. Antonopoulos, P. Balaji, C. T. Brown, C. T. Brown, N. Desai, J. A. Eisen, D. Evers, D. Field, W. Feng, D. Huson, J. Jansson, R. Knight, J. Knight, E. Kolker, K. Konstantindis, J. Kostka, N. Kyrpides, R. Mackelprang, A. McHardy, C. Quince, J. Raes, A. Sczyrba, A. Shade, and R. Stevens. 2010. Meeting report: The terabase metagenomics workshop and the vision of an Earth microbiome project. Stand. Genomic Sci. 3:243248. https://doi.org/10.4056/sigs.1433550.

Gröhn, Y. T., D. J. Wilson, R. N. González, J. A. Hertl, G. Bennett, and Y. H. Schukken. 2004. Effect of pathogen-specific clinical mastitis on milk yield in dairy cows. J. Dairy Sci. 87:3358-3374. https: //doi.org/10.3168/jds.S0022-0302(04)73472-4.

Hiitiö, H., H. Simojoki, P. Kalmus, J. Holopainen, S. Pyörälä, and S. Taponen. 2016. The effect of sampling technique on PCRbased bacteriological results of bovine milk samples. J. Dairy Sci. 99:6532-6541. https://doi.org/10.3168/jds.2015-10811.

Hiitiö, H., J. Vakkamäki, H. Simojoki, T. Autio, J. Junnila, J. Pelkonen, S. Pyörälä, and S. Taponen. 2017. Prevalence of subclinical mastitis in Finnish dairy cows: Changes during recent decades and impact of cow and herd factors. Acta Vet. Scand. 59:22. https:// doi.org/10.1186/s13028-017-0288-x.

Hill, A. W. 1981. Factors influencing the outcome of Escherichia coli mastitis in the dairy cow. Res. Vet. Sci. 31:107-112.

Hogeveen, H., S. Pyörälä, K. Persson Waller, J. S. Hogan, T. J. G. M. Lam, S. P. Oliver, Y. H. Schukken, H. W. Barkema, and J. E. Hillerton. 2011. Current status and future challenges in mastitis research. Pages 36-48 in Proc. 50th Annu. Mtg. Natl. Mastitis Counc., Arlington, VA. National Mastitis Council, Madison, WI.

Hunt, K. M., J. A. Foster, L. J. Forney, U. M. Schutte, D. L. Beck, Z. Abdo, L. K. Fox, J. E. Williams, M. K. McGuire, and M. A. McGuire. 2011. Characterization of the diversity and temporal stability of bacterial communities in human milk. PLoS One 6:e21313. https://doi.org/10.1371/journal.pone.0021313.

Jost, T., C. Lacroix, C. P. Braegger, F. Rochat, and C. Chassard. 2014. Vertical mother-neonate transfer of maternal gut bacteria via breastfeeding. Environ. Microbiol. 16:2891-2904. https://doi .org/10.1111/1462-2920.12238.

Kuehn, J. S., P. J. Gorden, D. Munro, R. Rong, Q. Dong, P. J. Plummer, C. Wang, and G. J. Phillips. 2013. Bacterial community profiling of milk samples as a means to understand culture-negative 
bovine clinical mastitis. PLoS One 8:e61959. https://doi.org/10 .1371/journal.pone.0061959.

Lago, A., S. M. Godden, R. Bey, P. L. Ruegg, and K. Leslie. 2011a. The selective treatment of clinical mastitis based on on-farm culture results: I. Effects on antibiotic use, milk withholding time, and short-term clinical and bacteriological outcomes. J. Dairy Sci. 94:4441-4456. https://doi.org/10.3168/jds.2010-4046.

Lago, A., S. M. Godden, R. Bey, P. L. Ruegg, and K. Leslie. 2011b. The selective treatment of clinical mastitis based on on-farm culture results: II. Effects on lactation performance, including clinical mastitis recurrence, somatic cell count, milk production, and cow survival. J. Dairy Sci. 94:4457-4467. https://doi.org/10.3168/jds .2010-4047.

Ley, R. E., P. J. Turnbaugh, S. Klein, and J. I. Gordon. 2006. Microbial ecology: Human gut microbes associated with obesity. Nature 444:1022-1023. https://doi.org/10.1038/4441022a.

Lima, S. F., M. L. Bicalho, and R. C. Bicahlo. 2018. Evaluation of milk sample fractions for characterization of milk microbiota from healthy and clinical mastitis cows. PLoS One 13:e0193671. https:/ /doi.org/10.1371/journal.pone.0193671.

Lima, S. F., A. G. Teixeira, F. S. Lima, E. K. Ganda, C. H. Higgins, G. Oikonomou, and R. C. Bicalho. 2017. The bovine colostrum microbiome and its association with clinical mastitis. J. Dairy Sci. 100:3031-3042. https://doi.org/10.3168/jds.2016-11604.

Lozupone, C., and R. Knight. 2005. UniFrac: A new phylogenetic method for comparing microbial communities. Appl. Environ. Microbiol. 71:8228-8235. https://doi.org/10.1128/AEM.71.12.8228 $-8235.2005$

McDonald, D., M. N. Price, J. Goodrich, E. P. Nawrocki, T. Z. DeSantis, A. Probst, G. L. Andersen, R. Knight, and P. Hugenholtz. 2012. An improved Greengenes taxonomy with explicit ranks for ecological and evolutionary analyses of bacteria and archaea. ISME J. 6:610-618. https://doi.org/10.1038/ismej.2011.139.

McDougall, S., J. Niethammer, and E. M. Graham. 2018. Antimicrobial usage and risk of retreatment for mild to moderate clinical mastitis cases on dairy farms following on-farm bacterial culture and selective therapy. N. Z. Vet. J. 66:98-107. https://doi.org/10 $.1080 / 00480169.2017 .1416692$

Mehrzad, J., D. Janssen, L. Duchateau, and C. Burvenich. 2008. Increase in Escherichia coli inoculum dose accelerates CD8+ T-cell trafficking in the primiparous bovine mammary gland. J. Dairy Sci. 91:193-201. https://doi.org/10.3168/jds.2007-0096.

Metzger, S. A., L. L. Hernandez, J. H. Skarlupka, G. Suen, T. M. Walker, and P. L. Ruegg. 2018. Influence of sampling technique and bedding type on the milk microbiota: Results of a pilot study. J. Dairy Sci. 101:6346-6356. https://doi.org/10.3168/jds.2017 -14212 .

National Mastitis Council. 2017. Laboratory Handbook on Bovine Mastitis. 2017 ed. No. 3. National Mastitis Council Inc., Madison, WI.

Oikonomou, G., M. L. Bicalho, E. Meira, R. E. Rossi, C. Foditsch, V. S. Machado, A. G. Teixeira, C. Santisteban, Y. H. Schukken, and R. C. Bicalho. 2014. Microbiota of cow's milk; distinguishing healthy, sub-clinically and clinically diseased quarters. PLoS One 9:e85904. https://doi.org/10.1371/journal.pone.0085904.

Oliveira, L., and P. L. Ruegg. 2014. Treatments of clinical mastitis occurring in cows on 51 large dairy herds in Wisconsin. J. Dairy Sci. 97:5426-5436. https://doi.org/10.3168/jds.2013-7756.

Oultram, J. W., E. K. Ganda, S. C. Boulding, R. C. Bicalho, and G. Oikonomou. 2017. A metataxonomic approach could be considered for cattle clinical mastitis diagnostics. Front. Vet. Sci. 4:36. https: //doi.org/10.3389/fvets.2017.00036.

Pinzón-Sánchez, C., and P. L. Ruegg. 2011. Risk factors associated with short-term post-treatment outcomes of clinical mastitis. J. Dairy Sci. 94:3397-3410. https://doi.org/10.3168/jds.2010-3925.

Pol, M., and P. L. Ruegg. 2007. Relationship between antimicrobial drug usage and antimicrobial susceptibility of gram-positive mastitis pathogens. J. Dairy Sci. 90:262-273. https://doi.org/S0022 -0302(07)72627-9.

Pyörälä, S., L. Kaartinen, H. Kack, and V. Rainio. 1994. Efficacy of two therapy regimens for treatment of experimentally induced
Escherichia coli mastitis in cows. J. Dairy Sci. 77:453-461. https:/ /doi.org/S0022-0302(94)76973-3.

Roberson, J. R., L. D. Warnick, and G. Moore. 2004. Mild to moderate clinical mastitis: Efficacy of intramammary amoxicillin, frequent milk-out, a combined intramammary amoxicillin, and frequent milk-out treatment versus no treatment. J. Dairy Sci. 87:583-592. https://doi.org/S0022-0302(04)73200-2.

Rodrigues, M. X., S. F. Lima, S. G. Canniatti-Brazaca, and R. C. Bicalho. 2017. The microbiome of bulk tank milk: Characterization and associations with somatic cell count and bacterial count. J. Dairy Sci. 100:2536-2552. https://doi.org/10.3168/jds.2016-11540.

Ruegg, P. L. 2017. A 100-Year Review: Mastitis detection, management, and prevention. J. Dairy Sci. 100:10381-10397. https://doi .org/10.3168/jds.2017-13023.

Schepers, A. J., T. J. Lam, Y. H. Schukken, J. B. Wilmink, and W. J. Hanekamp. 1997. Estimation of variance components for somatic cell counts to determine thresholds for uninfected quarters. J. Dairy Sci. 80:1833-1840. https://doi.org/10.3168/jds.S0022 -0302(97)76118-6.

Schukken, Y. H., J. Hertl, D. Bar, G. J. Bennett, R. N. González, B. J. Rauch, C. Santistebal, H. F. Schulte, L. Tauer, F. L. Welcome, and Y. T. Gröhn. 2009. Effects of repeated gram-positive and gramnegative clinical mastitis episodes on milk yield loss in Holstein dairy cows. J. Dairy Sci. 92:3091-3105. https://doi.org/10.3168/ jds.2008-1557.

Suojala, L., L. Kaartinen, and S. Pyorala. 2013. Treatment for bovine Escherichia coli mastitis - An evidence-based approach. J. Vet. Pharmacol. Ther. 36:521-531. https://doi.org/10.1111/jvp.12057.

Stevens, M., S. Piepers, K. Supre, J. Dewulf, and S. De Vliegher. 2016. Quantification of antimicrobial consumption in adult cattle on dairy herds in Flanders, Belgium, and associations with udder health, milk quality, and production performance. J. Dairy Sci. 99:2118-2130. https://doi.org/10.3168/jds.2015-10199.

Tolosa, T., J. Verbeke, Z. Ayana, S. Piepers, K. Supré, and S. DeVliegher. 2015. Pathogen group specific risk factors for clinical mastitis intramammary infection and blind quarters at the herd, cow and quarter level in smallholder dairy farms in Jimma, Ethiopia. Prev. Vet. Med. 120:306-312. https://doi.org/10.1016/j.prevetmed.2015 .05 .001 .

Turnbaugh, P. J., V. K. Ridaura, J. J. Faith, F. E. Rey, R. Knight, and J. I. Gordon. 2009. The effect of diet on the human gut microbiome: A metagenomic analysis in humanized gnotobiotic mice. Sci. Transl. Med. 1:6ra14. https://doi.org/10.1126/scitranslmed .3000322 .

Vasquez, A. K., D. V. Nydam, M. B. Capel, S. Eicker, and P. D. Virkler. 2017. Clinical outcome comparison of immediate blanket treatment versus a delayed pathogen-based treatment protocol for clinical mastitis in a New York dairy herd. J. Dairy Sci. 100:29923003. https://doi.org/10.3168/jds.2016-11614.

Vázquez-Baeza, Y., M. Pirrung, A. Gonzalez, and R. Knight. 2013. EMPeror: A tool for visualizing high-throughput microbial community data. Gigascience 2:16. https://doi.org/10.1186/2047 $-217 \mathrm{X}-2-16$.

Verdier-Metz, I., G. Gagne, S. Bornes, F. Monsallier, P. Veisseire, C. Delbés-Paus, and M. C. Montel. 2012. Cow teat skin, a potential source of diverse microbial populations for cheese production. Appl. Environ. Microbiol. 78:326-333. https://doi.org/10.1128/ AEM.06229-11.

Ward, T. L., S. Hosid, I. Ioshikhes, and I. Altosaar. 2013. Human milk metagenome: A functional capacity analysis. BMC Microbiol. 13:116. https://doi.org/10.1186/1471-2180-13-116.

Wellenberg, G. J., W. H. M. van der Poel, and J. T. Van Oierschot. 2002. Viral infections and bovine mastitis: A review. Vet. Microbiol. 88:27-45. https://doi.org/10.1016/S0378-1135(02)00098-6.

Young, W., B. C. Hine, O. A. M. Wallace, M. Callaghan, and R. C. Bibiloni. 2015. Transfer of intestinal bacterial components to mammary secretions in the cow. PeerJ 3:e888. https://doi.org/10 $.7717 /$ peerj. 888 . 